\title{
Electric charge conversable drug liposomes enable to enhance treatment efficacy of breast cancer
}

Yao Zhao*, Jing Bai*, Qian Luo*, Jing-Ying Zhang, Jia-Rui Xu, Jia-Lun Duan, Yan Yan, Li-Min $\mathrm{Mu}$, Wan-Liang $\mathrm{Lu}^{\#}$

Beijing Key Laboratory of Molecular Pharmaceutics and New Drug System, State Key Laboratory of Natural and Biomimetic Drugs, and School of Pharmaceutical Sciences, Peking University, Beijing 100191, China

Submitted: June 14, 2019

Accepted: July 27, 2019

Published: July 29, 2019

\section{Graphical Abstract}

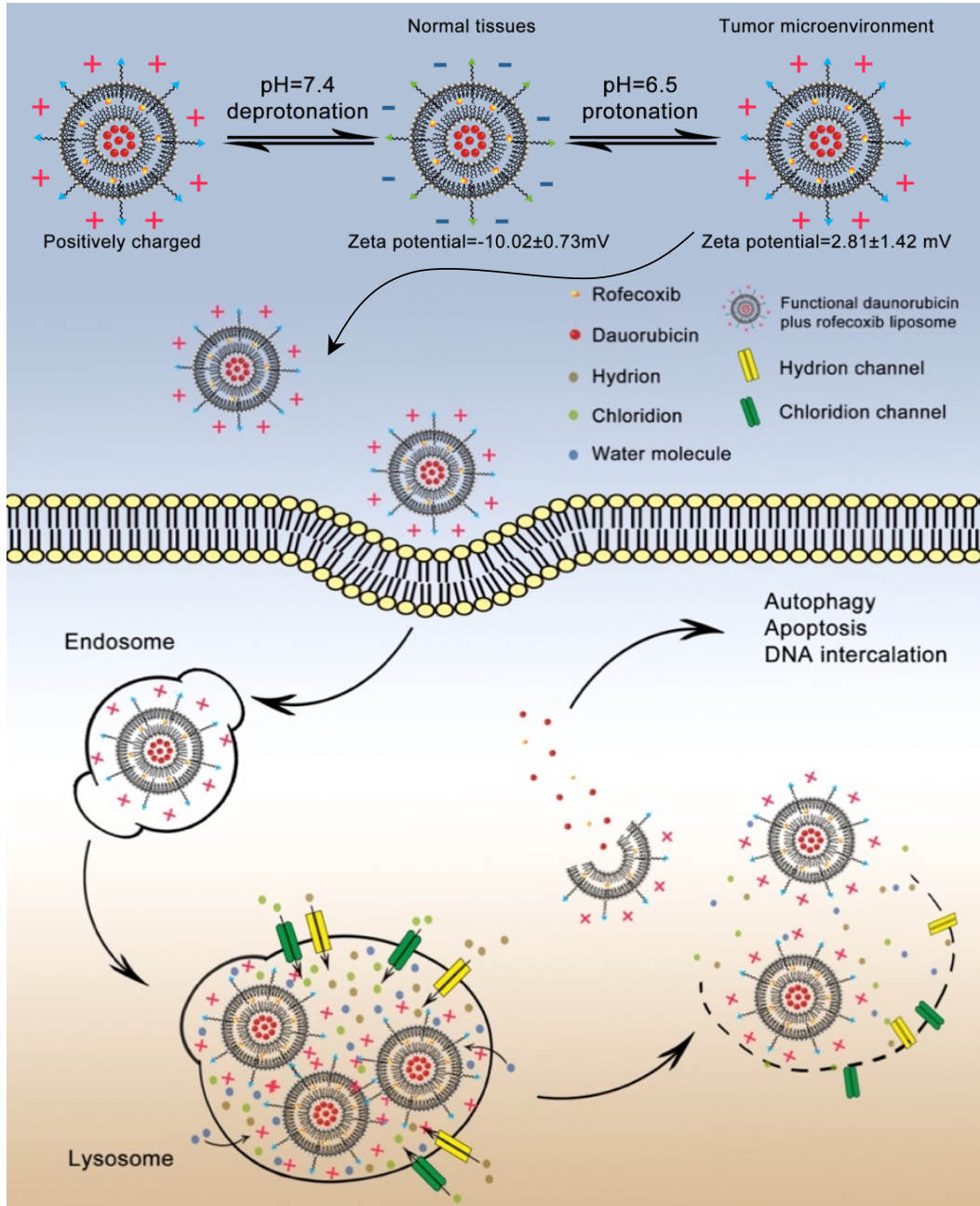

Electric charge convertable drug liposomes offer a broadly applicable strategy to enhance treatment efficacy against heterogeneous and refractory cancer cells in vitro and in vivo.

${ }^{*}$ These authors contributed equally to this work

\# Corresponding author: Wan-Liang Lu, PhD, Professor and Vice Dean, School of Pharmaceutical Sciences, Peking University, Beijing 100191, China, luwl@,bjmu.edu.cn, Tel.: +861082802683, Fax: $+861082802683$ 


\section{Abstract}

Intrinsic drug resistance has been demonstrated in different types of breast cancer cells, leading to the recurrence of disease after treatment. Here, we report a functional drug liposome that enables electric charge conversion in the weak acidic milieu of cancer to enhance the treatment efficacy of different breast cancers. The functional drug liposomes were developed by encapsulating daunorubicin and rofecoxib, and modified with new functional material, D-alpha tocopherol acid succinate-polyethylene glycol-glutarate (TPGS $_{1000}$-glutarate). The results demonstrated that the liposomes promoted the effects of cellular uptake and lysosomal escape, followed by targeting the mitochondria. Consequently, the electric charge conversable drug liposomes significantly enhanced the treatment efficacy by initiating a cascade of reactions through inducing autophagy and apoptosis in different breast cancer cells. In conclusion, the electric charge conversable drug liposomes enable to enhance treatment efficacy of different breast cancers, and hence the study could offer a broadly applicable strategy to enhance efficacy against heterogeneous and refractory cancer cells.

\section{Key Words:}

Electric charge conversion, functional drug liposomes, daunorubicin, rofecoxib, breast cancer

\section{Rationale and Purpose}

Intrinsic drug resistance of breast cancer cells always leads to the recurrence of disease after treatment. To circumvent this problem, we fabricated a novel electric charge conversion drug liposome, which was developed by encapsulating daunorubicin and rofecoxib, and modified with new functional material, D-alpha tocopherol acid succinate-polyethylene glycolglutarate $\left(\mathrm{TPGS}_{1000}\right.$-glutarate). The functional drug liposome enables the drug to be endocytosed by heterogeneous drug-resistant cancer cells, followed by rapidly escaping from the lysosomes, hence enhancing drug efficacy in killing the refractory cancer cells. The electric charge conversable drug liposome could not only provide a platform to load various anticancer drugs for troubleshooting problems encountered in clinical treatment but also a facile, effective, safe and broadly applicable strategy to enhance efficacy against heterogeneous resistant and refractory cancer cells.

\section{Introduction}

Intrinsic drug resistance has been demonstrated in different types of cancers including breast cancer, $[1,2]$ and heterogeneity of cancer is one of the causes for the intrinsic drug resistance. Cancer heterogeneity may arise from genetic differences in which cancer tissue comprises a diverse subpopulation of cells. Different subgroups of cells have different sensitivity to the same drug, [3] and accordingly, they have different uptake capacity, leading to a clinical issue that the conventional chemotherapeutic agents cannot eliminate heterogeneous cancer cells completely.[4]

To circumvent this problem, we fabricated a novel electric charge conversion drug liposome which could significantly increase the drug uptake by different breast cancer cells, and then eliminate heterogeneous breast cancer cells through inducing autophagy and apoptosis. In the construct, daunorubicin was encapsulated as an anticancer agent, and rofecoxib was incorporated together as an agent for inducing autophagy and apoptosis. Furthermore, a newly synthesized conjugate of D-alpha tocopherol acid succinate-polyethylene glycol-glutarate (TPGS ${ }_{1000}$-glutarate) was modified onto the liposomes as the charge conversion material for promoting cellular uptake and lysosome escape in the breast cancer cells.

Daunorubicin is used widely for the treatment of various cancers. The anticancer effect of daunorubicin derives from its actions by DNA intercalation, reactive oxygen species (ROS) production, and interaction with DNA topoisomerases I and II. It damages cancer cells via multiple mechanisms that lead to their death. $[5,6]$ However, its efficacy is limited by heterogeneous drug resistance.[7]

Rofecoxib is a nonsteroidal antiinflammatory drug that is a selective inhibitor of cyclooxygenase-2 (COX-2).[8] Recent studies have revealed that COX-2 
overexpression is associated with poor survival of patients with breast cancer and that rofecoxib shows efficacy in reducing the risk of cancer recurrence.[6] We find that rofecoxib can induce autophagy and apoptosis in cancer cells.

Polyethylene glycol (PEG) modified drug liposome carriers can stay in the blood circulation system for a longer time, and produce superior accumulation in cancer tissue via the "enhanced permeability and retention" (EPR) effect.[9, 10] Based on the same rationale, TPGS ${ }_{1000}$, a PEG containing material, is also able to stay in the circulation for a longer time. Also, it can also enhance cellular uptake.[11] In this study, we newly synthesize a TPGS $_{1000}$-glutarate, which is a polymer with carboxyl pendant groups. At $\mathrm{pH} 7.4$, the carboxyl groups are deprotonated and the TPGS $_{1000}$-glutarate turns to be negatively charged; conversely, the synthesized conjugate $\mathrm{TPGS}_{1000}$-glutarate is positively charged by protonation in a weakly acidic environment of cancer, enabling that the $\mathrm{TPGS}_{1000}$-glutarate modified drug liposomes have electric charge conversion ability.

Here, we report that the functional drug liposomes can be endocytosed by two types of heterogeneous breast cancer cells: human breast cancer MCF-7 cells and triple-negative human breast cancer MDA-MB-231 cells, resulting in autophagy, apoptosis, and necrosis to eliminate breast cancer cells. Also, we further reveal the mechanisms at the organelle and molecular levels, followed by confirming the efficacy in breast cancer cell-bearing mice.

\section{Materials and Methods}

\section{Materials and cancer cells}

Daunorubicin hydrochloride and rofecoxib were purchased from Nanjing Tianzun Zezhong Chemicals, Co. Ltd. (Nanjing, China). Dicyclohexylcarbodiimide (DCC), 4dimethylaminopyridine (DMAP), D-atocopheryl polyethylene glycol 1000 succinate $\left(\mathrm{TPGS}_{1000}\right)$, sulforhodamine-B, and Sephadex G-50 were purchased from Sigma Aldrich (St. Louis, MO, USA). Glutaric acid were obtained from J\&K Scientific Ltd. (Beijing, China). Dimethyl sulphoxide DMSO was purchased from Amresco (Solon, OH, USA). Other reagents were from Beijing Chemical Reagents (Beijing, China).
Human breast cancer MCF-7 and triplenegative breast cancer MDA-MB-231 cells were purchased from the Institute of Basic Medical Science, Chinese Academy of Medical Science (Beijing, China). The cancer cells were cultured at $37^{\circ} \mathrm{C}$ under an atmosphere of $5 \%$ $\mathrm{CO}_{2}$. Culture medium for MCF-7 cells was RPMI-1640 medium (Macgene, Beijing, China) supplemented with $10 \%$ fetal bovine serum (FBS, Gibco, Beijing local agent, China), while culture medium for MDA-MB231 cells was Leibovitz's L15 medium (Macgene) supplemented with $10 \%$ fetal bovine serum (FBS, Gibco).

Female nu/nu nude mice (initially weighing 19-22g) were obtained from Vital River Laboratory Animal Center (Beijing, China), and kept under specific pathogen-free (SPF) condition with free access to standard food and water. All of the animal experiments adhered to the principles of care and use of laboratory animals and were approved by the Institutional Animal Care and Use Committee of Peking University.

Preparation and characterization of liposomes

TPGS $_{1000}$-glutarate was synthesized by conjugation of TPGS 1000 with glutaric acid.

Amounts of $0.2 \mathrm{mmol}$ glutaric acid, $0.1 \mathrm{mmol}$ DMAP, and $0.24 \mathrm{mmol}$ DCC were dissolved in $2 \mathrm{~mL}$ DMSO. The mixture was stirred for 2 hours using a magnetic stirrer under nitrogen gas protection. After addition of $0.04 \mathrm{mmol}$ TPGS $_{1000}$, the reaction mixture was further stirred for 24 hours at room temperature. The crude product was transferred into a dialysis tubing (cut-off MW, $1000 \mathrm{Da}$ ) and dialyzed against deionized water for another 48 hours to remove uncoupled glutaric acid, DMAP, DCC, and DMSO. Resultant was then lyophilized and stored at $-20^{\circ} \mathrm{C}$. The product was confirmed by MALDI-TOF-MS (Shimadzu, Japan).

To fabricate functional daunorubicin plus rofexocib liposomes, egg phosphatidylcholine (NOF, Japan), cholesterol, TPGS ${ }_{1000}$-glutarate, and rofecoxib were dissolved in chloroform at a ratio of 70:30:5:2.8 (mol/ $/ \mathrm{mol})$ into a pearshaped bottle. The solvent was removed by a rotary vacuum evaporator, and the lipid film was hydrated with $250 \mathrm{mM}$ ammonium sulfate by sonication in a water bath for $5 \mathrm{~min}$. Subsequently, the suspensions were treated 
using an ultrasonic cell disruptor for 10 minutes $(200 \mathrm{~W})$. The suspensions obtained were extruded through polycarbonate membranes (Millipore, Bedford, MA, USA) thrice using $400-\mathrm{nm}$ pore sizes, and then thrice using $200-$ $\mathrm{nm}$ pore sizes. The functional rofecoxib liposomes were then produced. The suspensions of functional rofecoxib liposomes were dialyzed (cut-off MW, 8,000-12,000 Da) in the phosphate-buffered saline $(137 \mathrm{mM}$ $\mathrm{NaCl}, 2.7 \mathrm{mM} \mathrm{KCl}, 8 \mathrm{mM} \mathrm{Na}_{2} \mathrm{HPO}_{4}$ and $2 \mathrm{mM}$ $\mathrm{KH}_{2} \mathrm{PO}_{4}, \mathrm{PBS} \mathrm{pH}$ 7.4) for 24 hours, and incubated with daunorubicin solution in a water bath at $60^{\circ} \mathrm{C}$ with continually shaking for 20 minutes (lipids: drug 20:1, w/w). The functional daunorubicin plus rofecoxib liposomes were produced.

Daunorubicin plus rofecoxib liposomes were similarly prepared by replacing TPGS $_{1000^{-}}$ glutarate with TPGS ${ }_{1000}$. Daunorubicin liposomes, and rofecoxib liposomes were prepared by using the same procedures as above, excluding the addition of rofecoxib or daunorubicin. Blank functional liposomes were similarly prepared, excluding the addition of rofecoxib and daunorubicin. In addition, two kinds of liposomes were also similarly prepared as the fluorescent probes for evaluating targeting effects, including DiR liposomes and targeting DiR liposomes (lipids: DiR $=200: 1$, $\mathrm{w} / \mathrm{w})$.

Particle sizes, polydispersity index (PDI) and zeta potential values were measured with a Nano Series Zen 4003 Zetasizer (Malvern Instruments Ltd., Malvern, UK). A transmission electron microscope (TEM, FEI Company, OR, US) was used to further observe the morphology of the liposomes. Both daunorubicin and rofecoxib were simultaneously measured by a highperformance liquid chromatography system (Agilent Technologies Inc. Cotati, CA, US) with gradient elution. The wavelengths were set at $254 \mathrm{~nm}$ for daunorubicin and $233 \mathrm{~nm}$ for rofecoxib.

The encapsulation efficiency (EE) of daunorubicin or rofecoxib was calculated using the formula: $\mathrm{EE}=\left(\mathrm{W}_{\text {encap }} / \mathrm{W}_{\text {total }}\right) \times 100 \%$, where $\mathrm{W}_{\text {encap }}$ is the measured amount of daunorubicin or rofecoxib in the liposome suspensions after passing over the Sephadex G-50 column, and $\mathrm{W}_{\text {total }}$ is the measured amount of daunorubicin or rofecoxib in the initial liposome suspensions.
In vitro release of daunorubicin or rofecoxib from the liposomes was performed by dialysis against the release medium containing serum protein ( $\mathrm{pH} 7.4$ PBS containing 10\% FBS) at 100 revolutions per minute at $37^{\circ} \mathrm{C}$. Daunorubicin or rofecoxib content in the release medium was measured by HPLC. The release rate $(\mathrm{RR}, \%)$ was calculated using the formula: $\mathrm{RR}=\left(\mathrm{W}_{\mathrm{i}} / \mathrm{W}_{\text {total }}\right) \times 100 \%$, where $\mathrm{W}_{\mathrm{i}}$ is the measured amount of daunorubicin or rofecoxib at the $i^{\text {th }}$ time-point in the release medium, and $\mathrm{W}_{\text {total }}$ is the total amount of daunorubicin or rofecoxib in the equal volume of liposome suspensions prior to dialysis. Each assay was repeated in triplicate.

\section{Assay for cellular uptake}

To estimate cellular uptake qualitatively, cancer cells were seeded onto culture plates. After treatment with different drug formulations, cancer cells were imaged and analyzed using confocal laser fluorescence microscopy (CLFM) or measured by flow cytometry.

To estimate the cellular uptake qualitatively, MCF-7 cells and MDA-MB-231 cells were seeded into chambered coverslips at a density of $1.5 \times 10^{5}$ cell/well. After incubation for 24 hours, the cells were treated with free daunorubicin, daunorubicin liposomes, and functional daunorubicin liposomes at a concentration of $10 \mu \mathrm{M}$ daunorubicin for another 6 hours. The cells were then washed with cold PBS (pH 7.4) three times and stained with Hoechst $33342(1 \mu \mathrm{g} / \mathrm{mL})$ for cell nucleus staining for 30 minutes. Finally, the cells were imaged and analyzed using a confocal laser scanning fluorescent microscope (Leica, Heidelberg, Germany). Daunorubicin was used as the fluorescent probe. The excitation was set at $488 \mathrm{~nm}$ and the emission was set at $560 \mathrm{~nm}$.

To evaluate the cellular uptake quantitatively, MCF-7 cells and MDA-MB-231 cells were seeded into six-well plates at a density of $3 \times$ $10^{5}$ cells/well and cultured for 24 hours. Prior to the experiment, the cells were washed twice with PBS ( $\mathrm{pH}$ 7.4) to remove the remnant growth medium and then incubated in serumfree culture medium containing free daunorubicin, daunorubicin liposomes or functional daunorubicin liposome at a concentration of $10 \mu \mathrm{M}$ daunorubicin. Blank culture medium was used as the blank control. 
After incubation for 6 hours, cells were washed three times with cold PBS and then resuspended in $300 \mu \mathrm{L}$ PBS. Daunorubicin fluorescence intensity was measured by FACScan flow cytometer (FACScan, Becton Dickinson, San Jose, CA) with 10,000 events collected. The excitation was set at $488 \mathrm{~nm}$ and the emission was set at $560 \mathrm{~nm}$. Each experiment was performed in triplicate.

\section{Lysosome escape}

To study lysosome escape, cancer cells were incubated with different drug formulations. Lysosomes were stained, imaged and analyzed using CLFM.

To study the lysosome escape in cancer cells, MCF-7 cells and MDA-MB-231 cells were seeded into chambered coverslips at $2 \times 10^{5}$ cells per well. After incubation for 24 hours, the cells were treated with free daunorubicin, daunorubicin liposomes, daunorubicin plus rofecoxib liposomes, and functional daunorubicin plus rofecoxib liposomes, and further incubated for 4 hours and 12 hours, respectively. The final concentration of daunorubicin was $10 \mu \mathrm{M}$. Control experiments were undertaken by the addition of blank medium. Then, cells were washed with PBS (pH7.4) and stained with $20 \mathrm{nM}$ LysoTracker Deep Red FM for 2 hours under an atmosphere of $5 \% \mathrm{CO}_{2}$ at $37^{\circ} \mathrm{C}$. Daunorubicin was used as the fluorescent probe. The cells were imaged and analyzed using CLFM (Leica). Composite images were created by overlapping the images from individual channels.

\section{Autophagy assay}

To evaluate autophagy and signaling pathways, cancer cells were seeded onto 96well culture plates. After incubation with different drug formulations, proteins were marked with antibodies, measured using the Operetta high-content analysis system, and calculated using the Columbus system. For details, refer to the Supporting Information.

\section{Apoptosis assay}

To evaluate the induction of apoptosis and ROS, cancer cells were harvested and stained after incubation with different drug formulations and assessed by flow cytometry. To evaluate apoptosis signaling pathways, related proteins were marked with antibodies after treatment. To evaluate colocalization with mitochondria, the latter was stained after treatment with different drug formulations, imaged and analyzed using CLFM.

To evaluate the apoptosis ratio, MCF-7 cells and MDA-MB-231 cells were seeded at a density of $4 \times 10^{5}$ cells/well in 6-well culture plates. After incubation for 24 hours, the cells were treated with free daunorubicin, daunorubicin liposomes, daunorubicin plus rofecoxib liposomes, and functional daunorubicin plus rofecoxib liposomes at a concentration of $10 \mu \mathrm{M}$ daunorubicin and/or $10 \mu \mathrm{M}$ rofecoxib. Culture medium was used as the blank control. After incubation for 12 hours, cells were harvested and stained with SYTOX Green and Annexin V-keyfluor 647 according to the protocol. Once stained, the cells were determined in 1 hour by flow cytometer (Gallios, Beckman Dickson, USA). Each assay was repeated in triplicate. Annexin v-kfluor647 and SYTOX Green were used as positive markers and cell populations were classified according to staining results. The lower left quadrant contains double-negative cells (normal cells), the upper left quadrant contains SYTOX Green single-positive cells (damaged cells), the lower right quadrant contains Annexin v-kfluor647 single-positive cells (early apoptotic cells) and the upper-right quadrant contains double-positive cells (late apoptotic cells).

To evaluate the apoptosis signaling pathway, MCF-7 cells and MDA-MB-231 cells were seeded at a density of 5000 cells/well in 96-well plates. After incubation for 24 hours, cells were treated with daunorubicin liposomes, daunorubicin plus rofecoxib liposomes, and functional daunorubicin plus rofecoxib liposomes at a concentration of $10 \mu \mathrm{M}$ daunorubicin and/or $10 \mu \mathrm{M}$ rofecoxib. Culture medium was added as a blank control. After incubation for 6 hours, the cells were fixed with $4 \%$ formaldehyde for 15 minutes, permeabilized with $0.5 \%$ Triton X-100 for 15 minutes and blocked with $10 \%$ goat serum that contained $0.3 \mathrm{M}$ glycine for 2 hours at room temperature. The cells were subsequently incubated with the primary antibody (antiCaspase 8, anti-Caspase 9, anti-Caspase 3, antiMcl-1, anti-Bcl-2; Sangon), and anti-Bax (Biotime, China) at $4{ }^{\circ} \mathrm{C}$ overnight, followed by incubation with the secondary antibody (Alexa Fluor 488- labeled goat anti-mouse antibody; 
OriGene) at room temperature for 2 hours. Both primary and secondary antibodies were properly diluted according to the kit instructions. Nuclei were stained with Hoechst $33342(1 \mu \mathrm{g} / \mathrm{mL})$ for 30 minutes at room temperature. The fluorescence intensity of each well was measured using the Operetta high content screening system and calculated with the Columbus system (PerkinElmer).

To evaluate the induced ROS, MCF-7 cells and MDA-MB-231 cells were seeded in 6-well plates at a density of $3 \times 10^{5}$ cells/well and incubated for 24 hours. Cells were treated with free daunorubicin, daunorubicin liposomes, daunorubicin plus rofecoxib liposomes, and functional daunorubicin plus rofecoxib liposomes at a concentration of $10 \mu \mathrm{M}$ daunorubicin and/or $10 \mu \mathrm{M}$ rofecoxib. Culture medium was used as the blank control. After incubation for 6 hours, cells were stained with $1 \mu \mathrm{M}$ DCFH-DA (Biotime) for 10 minutes. The cells were then washed, harvested and resuspended in PBS (pH7.4) and determined immediately by flow cytometry as above.

To evaluate the co-localization effect with mitochondria, MCF-7 cells and MDA-MB-231 cells were seeded into chambered coverslips at $2 \times 10^{5}$ cells per well. After incubation for 24 hours, cells were treated with free daunorubicin, daunorubicin liposomes, daunorubicin plus rofecoxib liposomes and functional daunorubicin plus rofecoxib liposomes for 12 hours. The final concentration of daunorubicin was $10 \mu \mathrm{M}$. Control experiments were undertaken by the addition of blank medium. Then, cells were washed with PBS (pH 7.4) and stained with $100 \mathrm{nM}$ MitoTracker Deep Red FM for 30 minutes. Daunorubicin was used as the fluorescent probe, and composite images were created by overlapping the images from individual channels.

\section{Cytotoxicity assay}

To evaluate cytotoxicity, the survival of cancer cells was determined using a sulforhodamine B (SRB) colorimetric assay after treatment with different drug formulations.

To evaluate cytotoxicity, MCF-7 cells and MDA-MB-231 cells were seeded at a density of 7200 cells/well in 96-well culture plates and cultured for 24 hours. In free drug treatments, cells were then treated with serial concentrations of free daunorubicin, and free daunorubicin plus free rofecoxib. The concentration of daunorubicin was in the range of $0-1.0 \mu \mathrm{M}$ for MCF-7 cells, and $0-3.0 \mu \mathrm{M}$ for MDA-MB-231 cells. The concentration of rofecoxib was in the range of $1.0-5.0 \mu \mathrm{M}$ for MCF-7 cells, and 2.5 - 10.0 $\mu \mathrm{M}$ for MDA-MB231 cells. In liposome treatments, cells were treated with blank functional liposomes, rofecoxib liposomes, daunorubicin liposomes, daunorubicin plus rofecoxib liposomes, and functional daunorubicin plus rofecoxib liposomes. Both concentrations of daunorubicin and rofecoxib were in the range of $0-3.0 \mu \mathrm{M}$ (daunorubicin: rofecoxib $=1: 1$, $\mu \mathrm{M} / \mu \mathrm{M})$. After incubation for another 48 hours, the inhibitory effect was assayed with SRB assay. The survival rate was calculated using the following formula: Survival $\%=(A 540 \mathrm{~nm}$ for treated cells $/$ A540 nm for control cells $) \times 100 \%$, where A540 $\mathrm{nm}$ represents the absorbance value.

\section{In vivo imaging}

To evaluate drug distribution and anticancer efficacy in vivo, breast cancer cells were xenografted in female $\mathrm{Nu} / \mathrm{Nu}$ nude mice. To image drug distribution, fluorescence and radiographic images were captured using an in vivo imaging system at varying time-points after injection of DiR-labeled formulations.

To evaluate the drug distribution and anticancer efficacy in vivo, female $\mathrm{Nu} / \mathrm{Nu}$ nude mice were included for the studies. Briefly, approximately $6 \times 10^{6}$ MCF-7 cells were resuspended in $200 \mu \mathrm{L}$ serum-free 1640 culture medium and injected subcutaneously into the right flank of the mouse.

To image drug distribution, functional DiR liposomes were used as the fluorescent probe. 12 female $\mathrm{Nu} / \mathrm{Nu}$ nude mice were inoculated with MCF-7 cells as above. When cancer tissue reached approximately $1000 \mathrm{~mm} 3$ in volume, the cancer-bearing mice were randomly divided into four groups (3 per group). Afterwards, different formulations were administered to mice via the tail vein. The drug administration groups were set as follows: (1) physiological saline; (2) free DiR $(2.0 \mathrm{mg} / \mathrm{kg})$; (3) DiR liposomes $(2.0 \mathrm{mg} / \mathrm{kg})$; and (4) functional DiR liposomes $(2.0 \mathrm{mg} / \mathrm{kg})$. The mice were then anesthetized with isoflurane. Fluorescent radiographic images were captured using an in 
vivo imaging system (Carestream, Fx Pro, USA) at varying time-points $(1,2,3,6,12,24$ and 36 hours). The mice were sacrificed by cervical dislocation at 36 hours to collect cancer masses, hearts, livers, spleens, lungs, and kidneys. The fluorescent and radiographic images were also captured for all ex vivo tissues

\section{Anticancer efficacy}

When tumors reached about $100 \mathrm{~mm}^{3}$ in volume, the cancer-bearing mice were randomly divided into five groups (6 per group). At day $10,12,14,16$ and 18 postinoculation, different formulations were administered to mice via tail vein at a dose of 5 $\mathrm{mg} / \mathrm{kg}$ daunorubicin (or daunorubicin: rofecoxib $=1: 1, \mathrm{~mol} / \mathrm{mol}$ ), respectively. The drug administration groups were set as follows: (1) physiological saline; (2) free daunorubicin; (3) daunorubicin liposomes; (4) daunorubicin plus rofecoxib liposomes; and (5) functional daunorubicin plus rofecoxib liposomes. Physiological saline was administered as a blank control. Cancer volumes were measured every day with a caliper, and weight changes of mice were monitored every day with a weighing scale. Cancer volumes (V) were calculated with the formula: $V=$ length $\times$ width $^{2} / 2\left(\mathrm{~mm}^{3}\right)$, and cancer volume ratio was evaluated with the formula: $\mathrm{R}=\mathrm{V}_{\text {ith day }} / \mathrm{V}_{\text {9th day. }}$. The cancer-bearing mice were sacrificed at day 20 by cervical dislocation. Cancer masses were carefully isolated.

\section{Statistical analysis}

Data are the mean \pm standard deviation. Oneway analysis of variance was used to determine significance among groups, after which post hoc tests with the Bonferroni correction were used for multiple comparisons between individual groups. $\mathrm{P}<0.05$ was considered significant.

\section{Results}

Fabrication of functional drug liposomes and electric charge conversion

To fabricate the functional drug liposomes, daunorubicin was encapsulated within the liposome vesicle by the ammonium sulfate gradient method. Lipophilic rofecoxib was incorporated into the lipid bilayer of the liposome. TPGS 1000 -glutarate was newly synthesized and inserted into the bilayer of the liposome (Figure 1A, Figure S1A). (a)

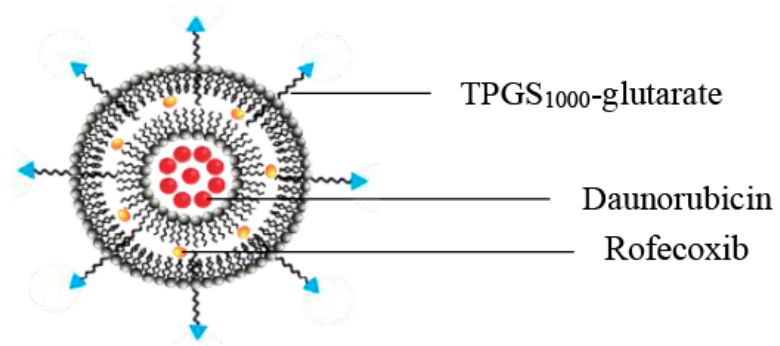

(b)

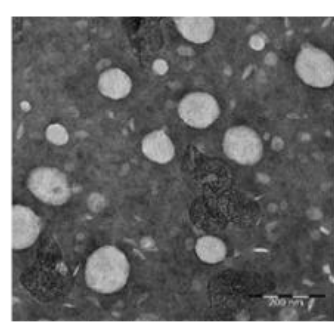

Figure 1: (a). Schematic representation of functional daunorubicin plus rofecoxib liposomes. (b) TEM images of functional daunorubicin

Morphologic analyses under transmission electron microscopy demonstrated that the functional drug liposomes displayed a smooth surface (Figure1 B). In the liposomes, the encapsulation efficiencies of daunorubicin and rofecoxib were $>91 \%$ and $>83 \%$, respectively. The mean particle size of functional drug liposomes was approximately $85 \mathrm{~nm}$ with a narrow polydispersity index $(0.20)$. In the simulated conditions, the zeta potentials showed that the functional daunorubicin plus rofecoxib liposomes were negatively charged but positively charged in a weak acidic condition (Figure 1C, Supplementary Table $\mathrm{S} 1)$. The releases from liposomes in vitro at 48 hours were $14.71 \pm 1.62 \%$ for daunorubicin (Figure S1B), and $24.62 \pm 0.76 \%$ for rofecoxib (Figure S1C). 
(c)

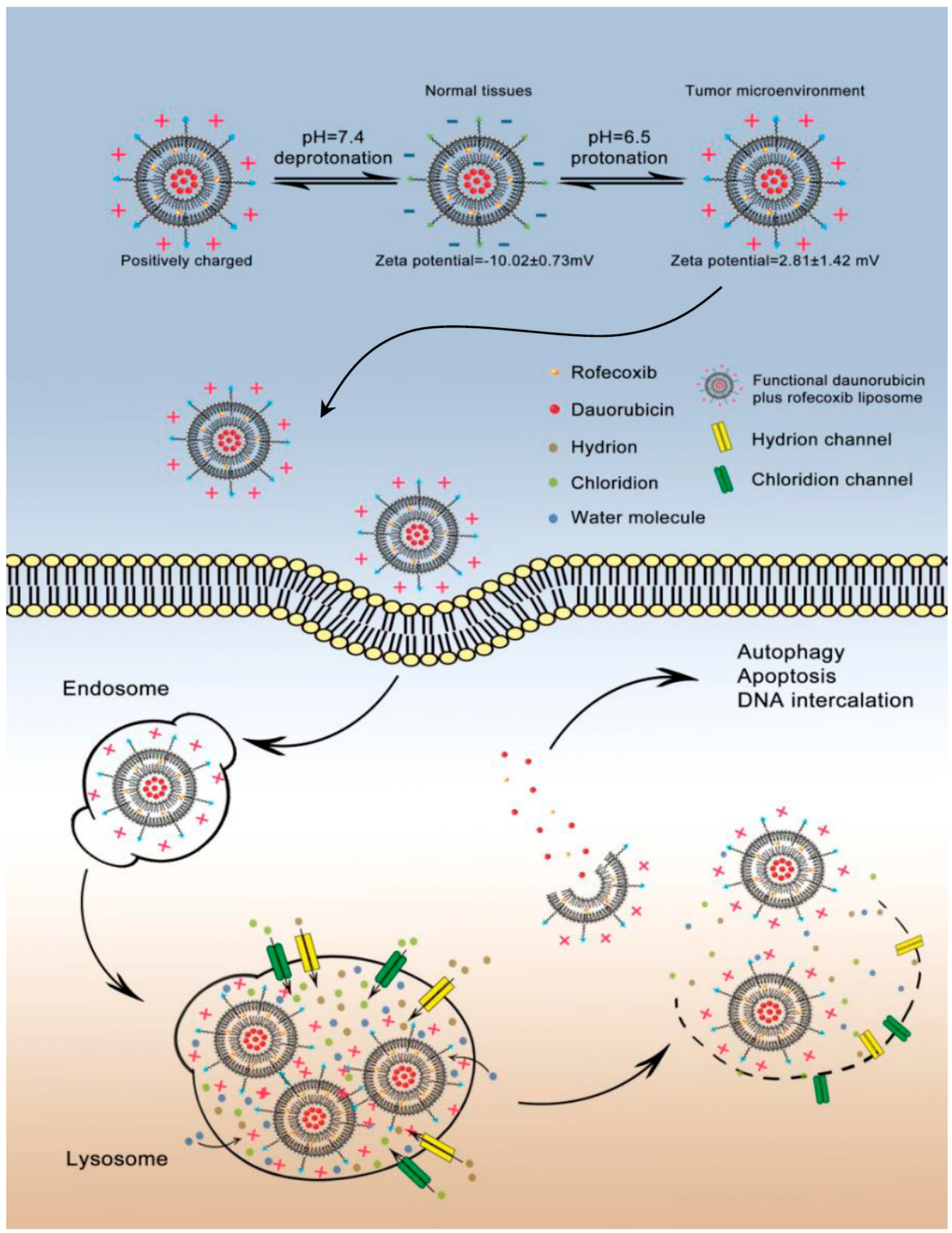

Figure 1c. Illustration for electric charge conversion of the functional daunorubicin plus rofecoxib liposomes. Notes: (a) Schematic representation of functional daunorubicin plus rofecoxib liposomes. (b) TEM images of functional daunorubicin plus rofecoxib liposomes. (c) Schematic diagram of functional liposomes electric charge conversion and lysosomal escape.

Promoting liposome cellular uptake by breast cancer cells

To identify cellular uptake, confocal laser fluorescence microscopy (CLFM) and flow cytometry were used for qualitative and quantitative purposes. In confocal images, daunorubicin showed green fluorescence, whereas nuclei were stained blue. Bright-green fluorescence was used to denote uptake by MCF-7 cells (Figure 2A) and MDA-MB-231 cells (Figure 2B). The results showed that the functional daunorubicin liposomes had the strongest cellular uptake as compared with the control. The semi-quantitative evaluation by flow cytometry revealed that the ranking of cellular uptake was free daunorubicin > functional daunorubicin liposomes $>$ daunorubicin liposomes $>$ blank medium in both types of cancer cells (Figure 2C and D, Supplementary Figure S2A and B). 

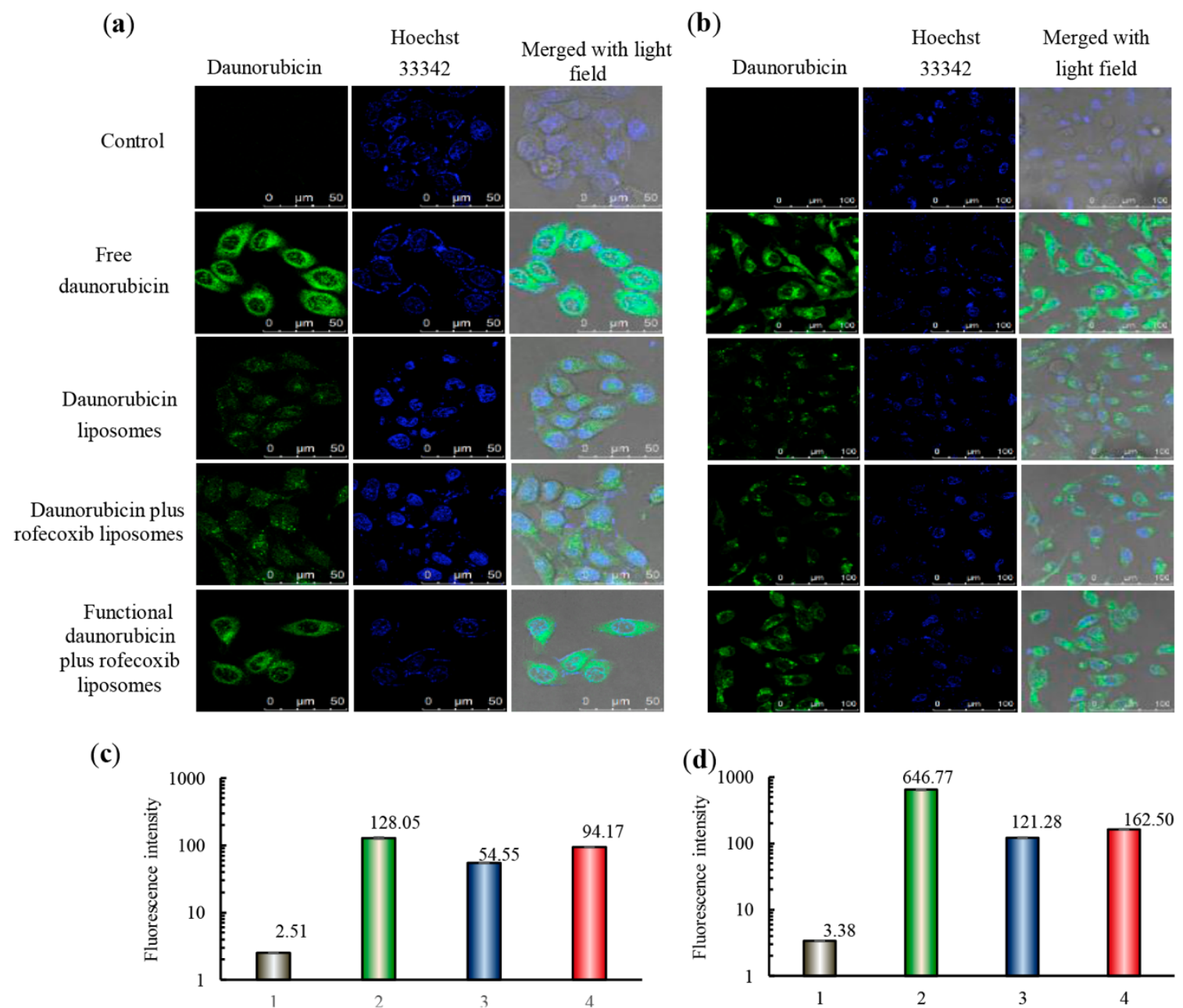

Figure 2. Cellular uptake by breast cancer cells after treatment. Notes:(a) Images of cellular uptake by MCF-7 cells by confocal laser fluorescent microscopy. (b) Images of cellular uptake by MDA-MB-231 cells by confocal laser fluorescent microscopy. (c) Cellular uptake by MCF-7 cells indicated by fluorescence intensity by flow cytometry. (d) Cellular uptake by $M D A-M B-231$ indicated by fluorescence intensity by flow cytometry. 1, blank control; 2, free daunorubicin; 3, daunorubicin liposomes; 4, functional daunorubicin liposomes. Data are presented as mean \pm standard deviation $(n=3)$.

\section{Enhancing lysosomal escape in breast cancer} cells

To understand the escape of liposomes from lysosomes after treatment with various formulations, the co-localization of liposomes with lysosomes of cancer cells was observed with CLFM. The lysosomes were stained as red fluorescence by LysoTracker Deep Red, whereas daunorubicin was marked as green fluorescence. Bright-yellow fluorescence was a composite image of red and green fluorescence, and thus used to indicate co-localization of liposomes into lysosomes. The results showed that the functional daunorubicin plus rofecoxib liposomes were co-localized into lysosomes at 4 hours and escaped from the lysosomes within 12 hours in both types of cancer cells (Figure
3A and B). Inducing autophagy and signaling pathway in breast cancer cells

To evaluate the induction of autophagy after treatment with various formulations, the induced autophagosomes in cancer cells were observed with an Operetta high-content imaging system and calculated using the Columbus system. After incubation with blank medium, free daunorubicin, daunorubicin liposomes, daunorubicin plus rofecoxib liposomes, and functional daunorubicin plus rofecoxib liposomes, the activity ratios of LC3B in MCF-7 cells were $1.00 \pm 0.03,1.05 \pm$ $0.05,1.10 \pm 0.04$ and $1.13 \pm 0.06$, respectively (Figure 4A and B). Similar results were observed in MDA-MB-231 cells (Supplementary Figure S3A and B). 


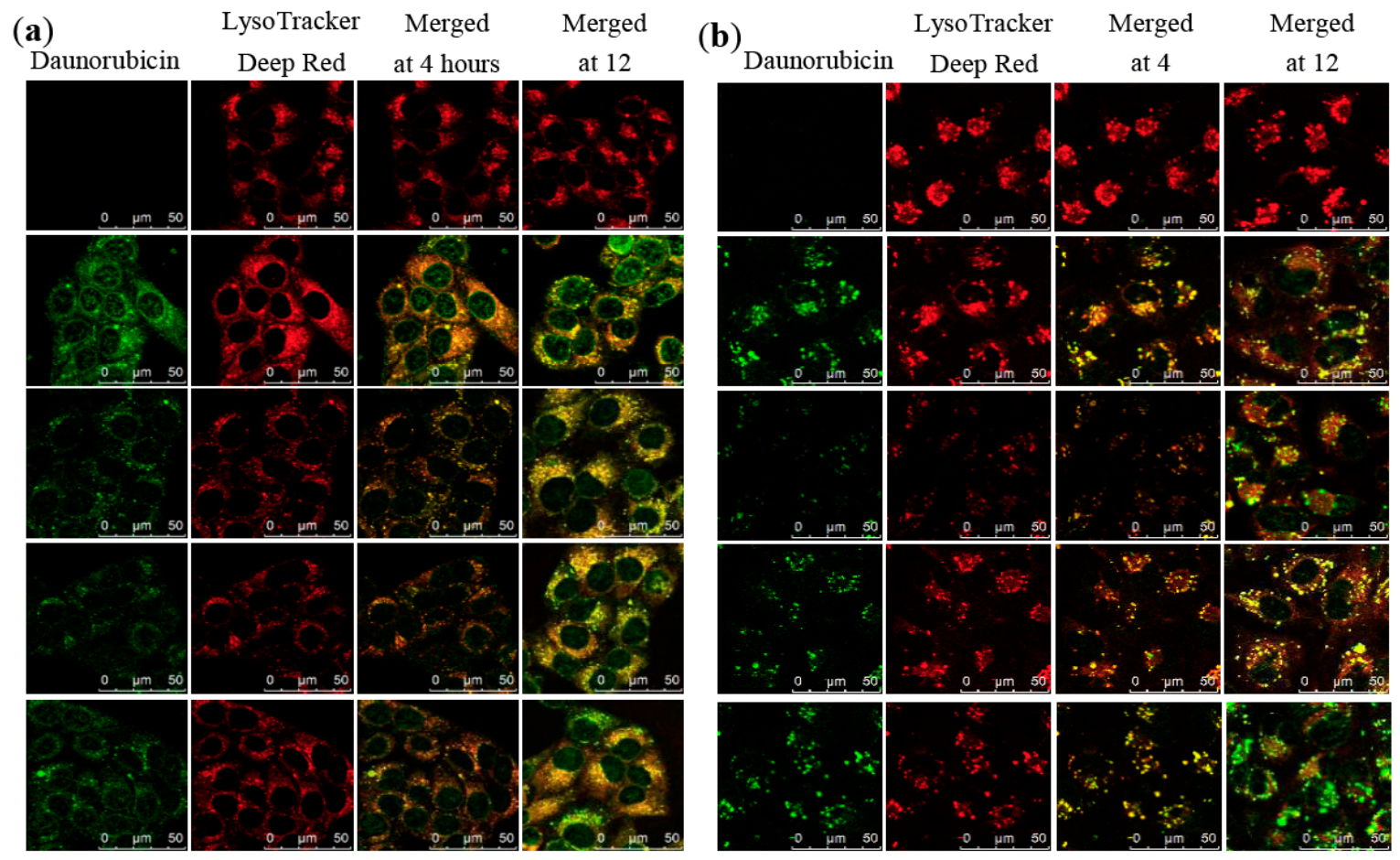

Figure 3. Lysosome co-localization and then lysosome escape of functional daunorubicin plus rofecoxib liposomes in breast cancer cells. Notes: The assays were performed by confocal laser fluorescent microscopy. (a) MCF-7 cells. (b) MDA-MB-231 cells. 1, blank control; 2, free daunorubicin; 3, daunorubicin liposomes; 4, daunorubicin plus rofecoxib liposomes; 5, functional daunorubicin plus rofecoxib liposomes.

To understand autophagy signaling pathway after treatment, expressions of autophagyassociated proteins were measured using the Operetta high-content imaging system and calculated using the Columbus system. As compared with controls, functional daunorubicin plus rofecoxib liposomes significantly increased the fluorescence intensities of phosphatase and tensin homolog (PTEN) and forkhead box protein O1 (FoxO1), but notably suppressed those of phosphatidylinositol 3-kinase (PI3K), protein kinase $\mathrm{B}$ (PKB), mammalian target of rapamycin (mTOR) and P53 (Figure 4C, Supplementary Figure S3C).

After treatment with blank medium, daunorubicin liposomes, daunorubicin plus rofecoxib liposomes, and functional daunorubicin plus rofecoxib liposomes, the activity ratios of biomarkers in the pathways in MCF-7 cells were $1.00 \pm 0.04,0.88 \pm 0.04,0.90$ \pm 0.04 and $0.84 \pm 0.03$ for PI3K; $1.00 \pm 0.09$, $0.74 \pm 0.08,0.61 \pm 0.05$ and $0.59 \pm 0.01$ for PKB; $1.00 \pm 0.04,0.80 \pm 0.06,0.79 \pm 0.04$ and $0.72 \pm 0.04$ for $\mathrm{mTOR} ; 1.00 \pm 0.08,0.79 \pm 0.06$,
$0.76 \pm 0.06$ and $0.68 \pm 0.03$ for $\mathrm{P} 53,1.00 \pm 0.04$, $1.06 \pm 0.07,1.07 \pm 0.06$ and $1.20 \pm 0.16$ for PTEN; $1.00 \pm 0.06,1.09 \pm 0.14,0.94 \pm 0.12$ and $1.23 \pm 0.18$ for FoxO1, respectively (Figure 4D). Similar results were observed in MDAMB-231 cells (Supplementary Figure S3D).

Initiating apoptosis and signaling pathway in breast cancer cells

To evaluate the induction of apoptosis after treatment with various formulations, the induced apoptosis in both types of cancer cells was observed by flow cytometry. After incubation with blank medium, free daunorubicin, daunorubicin liposomes, daunorubicin plus rofecoxib liposomes, and functional daunorubicin plus rofecoxib liposomes, the total percentages of apoptosis in MCF-7 cells were $5.91 \pm 0.50,21.33 \pm 3.46$, $12.49 \pm 2.12,23.28 \pm 3.50$ and $33.90 \pm 6.40$ (Figure 5A); and total percentages of apoptosis in MDA-MB-231 cells were $6.83 \pm 0.32,19.48$ $\pm 0.94,19.18 \pm 0.45,21.71 \pm 2.83$ and $31.90 \pm$ 4.13 , respectively (Supplementary Figure S4A). 


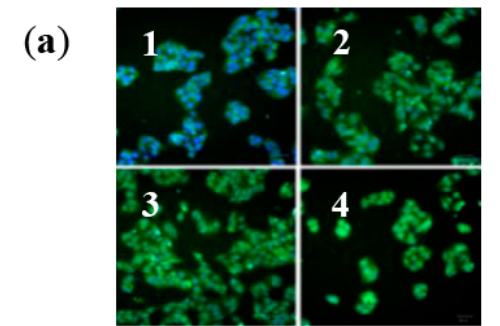

(b)

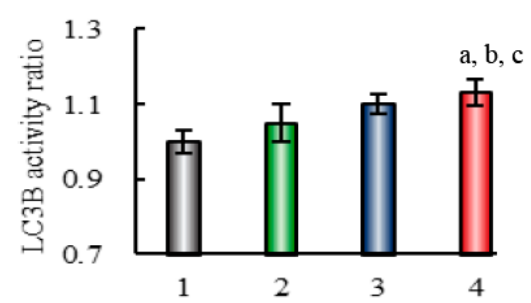

(c)

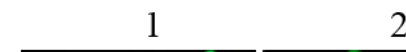

2
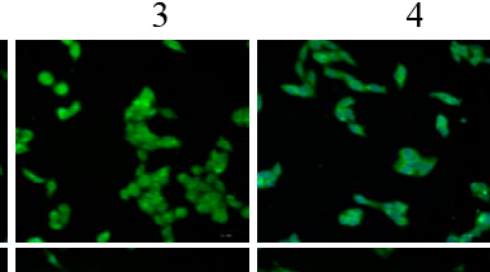

PKB
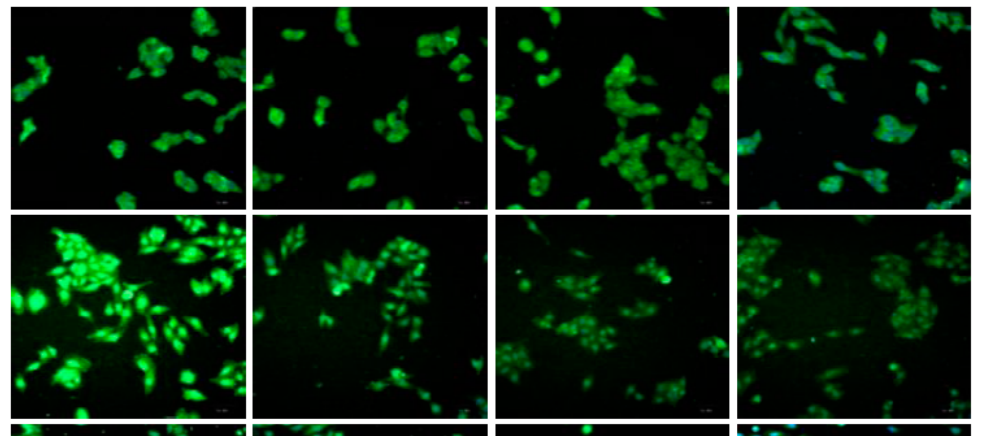

mTOR
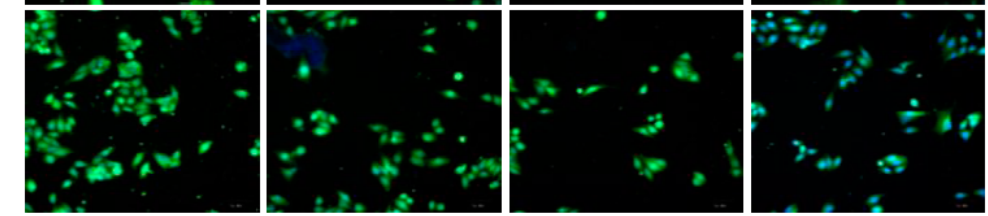

P53
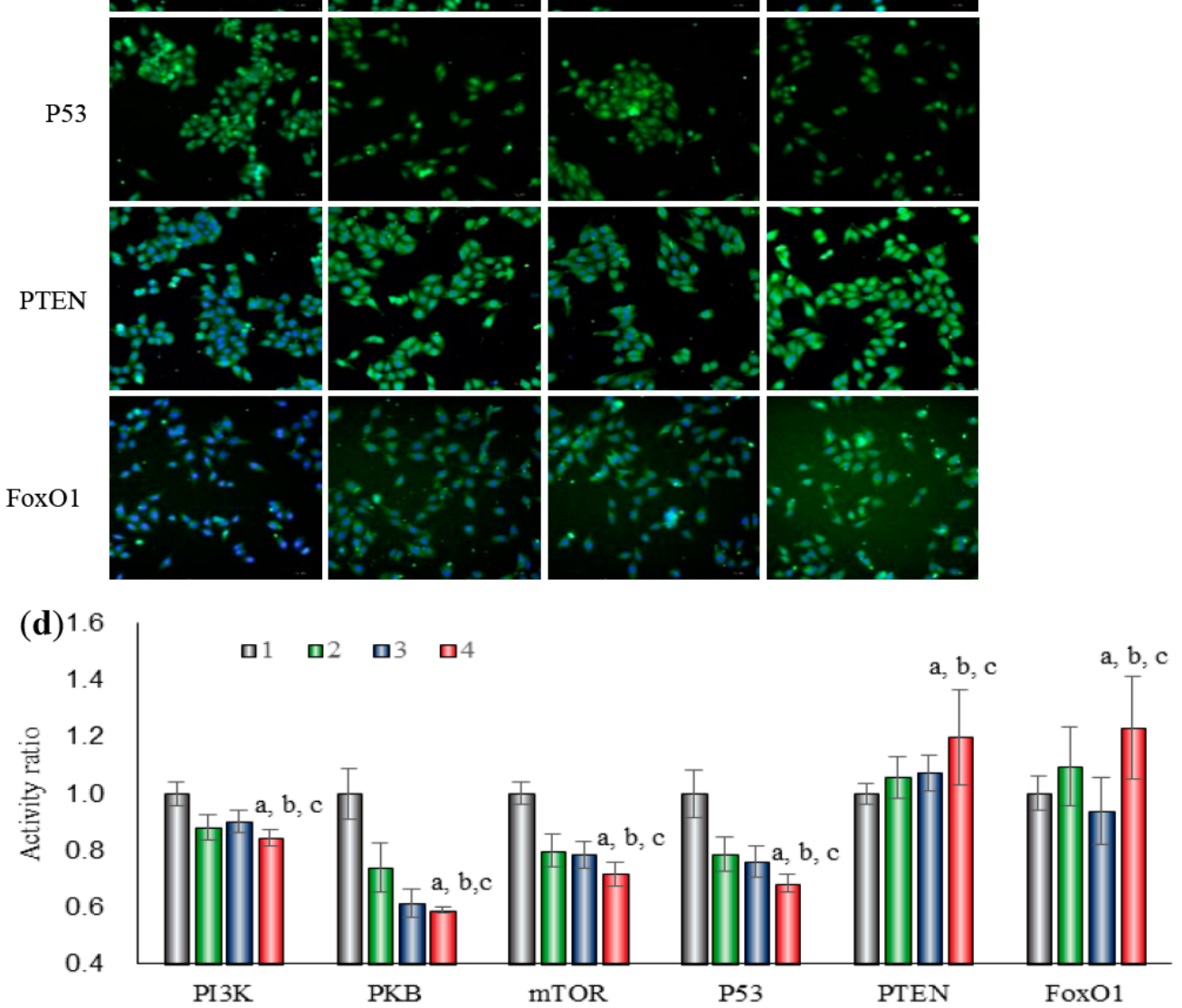

Figure 4. Induction of autophagy and changes of autophagy proteins in the signaling pathway in breast cancer cells Notes: The assays were performed by Operetta high-content imaging system with Columbus system. (a) Fluorescence intensities of LC3B in MCF-7 cells. (b) Activity ratios of LC3B in MCF-7 cells. (c) Autophagy proteins in the signaling pathways in MCF7 cells. (d) Autophagy proteins in the signaling pathways in MCF-7 cells. 1, blank control; 2, daunorubicin liposomes; 3 , daunorubicin plus rofecoxib liposomes; 4, functional daunorubicin plus rofecoxib liposomes. $P<0.05 ; a$, vs $1 ; b, v s 2 ; c$, vs 3. Data are presented as mean \pm standard deviation $(n=3)$. 
To understand apoptosis signaling pathways after treatment with various formulations, the qualitative and quantitative expressions of apoptosis-associated proteins were measured with the Operetta high-content imaging system and calculated with the Columbus system. As compared with the blank control, functional daunorubicin plus rofecoxib liposomes evidently increased the fluorescence intensities of caspase 3 , caspase 8 , caspase 9 , and proapoptotic protein Bax significantly, but significantly decreased the fluorescence intensities of the anti-apoptotic proteins Mcl-1 and Bcl-2, in both types of cancer cells (Figure 5B, Supplementary Figure S4B).

After treatment with blank medium, daunorubicin liposomes, daunorubicin plus rofecoxib liposomes, and functional daunorubicin plus rofecoxib liposomes, the activity ratios of the apoptotic enzymes, and pro-/anti-apoptotic proteins were $1.00 \pm 0.02$, $1.11 \pm 0.01,1.14 \pm 0.02$ and $1.21 \pm 0.04$ for caspase $8 ; 1.00 \pm 0.02,1.02 \pm 0.04,1.07 \pm 0.03$ and $1.13 \pm 0.04$ for caspase $9 ; 1.00 \pm 0.03,1.11$ $\pm 0.04,1.21 \pm 0.04$ and $1.29 \pm 0.06$ for caspase $3 ; 1.00 \pm 0.03,1.07 \pm 0.03,1.12 \pm 0.03$ and 1.30 \pm 0.04 for $\mathrm{Bax} ; 1.00 \pm 0.03,0.88 \pm 0.03,0.89 \pm$ 0.04 and $0.84 \pm 0.03$ for Mcl-1; $1.00 \pm 0.04$, $0.80 \pm 0.05,0.84 \pm 0.06$ and $0.76 \pm 0.05$ for Bcl2, respectively (Figure $5 \mathrm{C}$ and $\mathrm{D}$, Supplementary Figure S4B and C).

After treatment with various formulations, the ranking for the induced reactive oxygen species (ROS) was functional daunorubicin plus rofecoxib liposomes $>$ daunorubicin plus rofecoxib liposomes $>$ daunorubicin liposomes $>$ free daunorubicin $>$ blank medium (Figure 5E, Supplementary Figure S4E). Accordingly, the activity ratios of ROS were $1.00 \pm 0.08,2.58 \pm 0.24,3.17 \pm 0.03,3.43 \pm$ 0.19 and $3.95 \pm 0.12$, respectively (Figure $5 \mathrm{~F}$, Supplementary Figure S4F).

The co-localization of daunorubicin with mitochondria was observed by CLFM. Mitochondria were stained red, whereas lightgreen fluorescence was used to denote formulations containing daunorubicin. The results showed that, after 12 hours of incubation, the functional daunorubicin plus rofecoxib liposomes accumulated selectively into the mitochondria of breast cancer cells (Figure S5). (a)
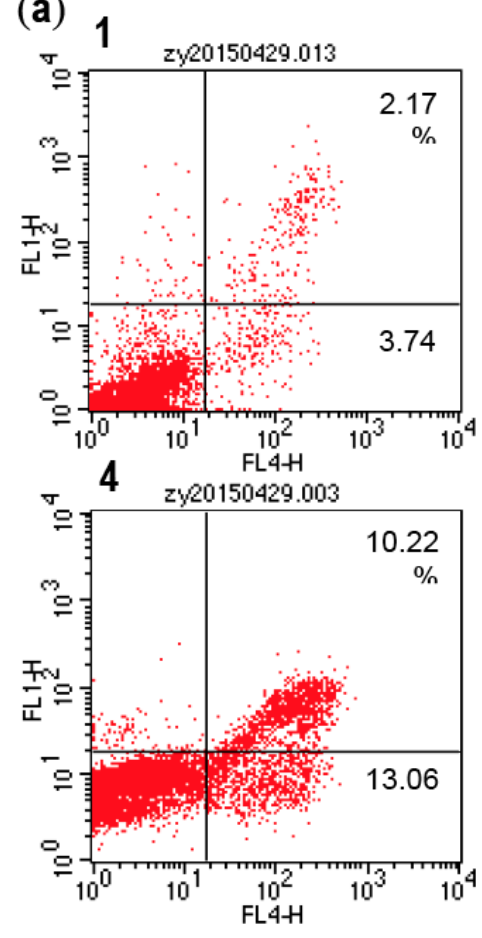
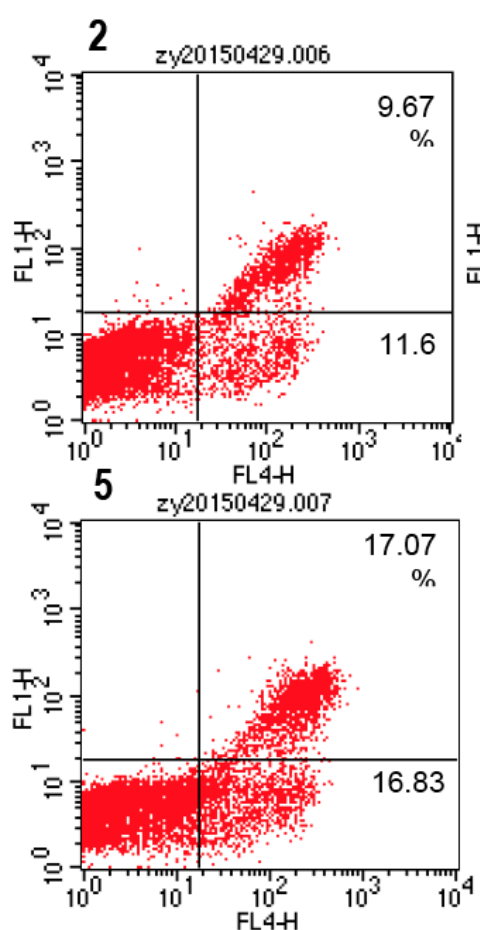
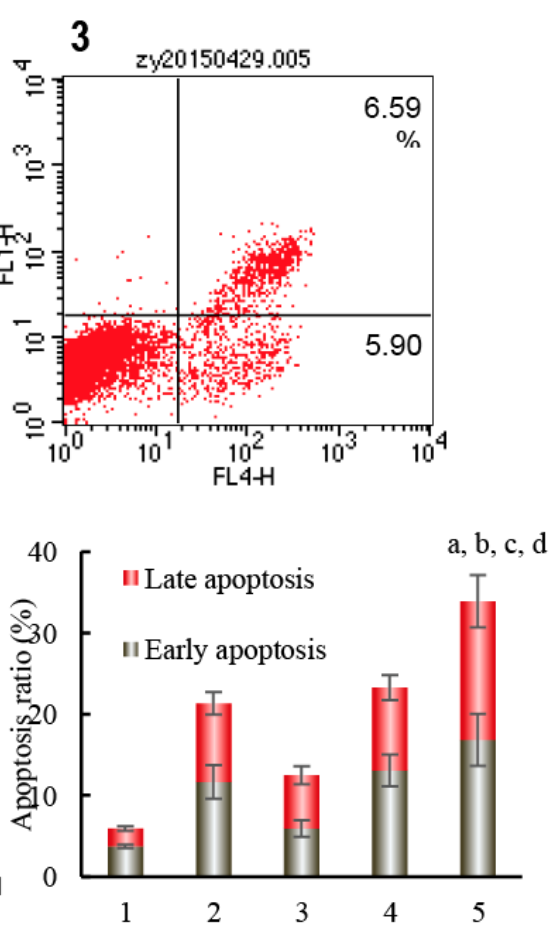

Figure 5a. Induction of apoptosis and changes of apoptosis proteins in the signaling pathway in breast cancer cells. (a) Apoptosis of MCF-7 cells by flow cytometry; 


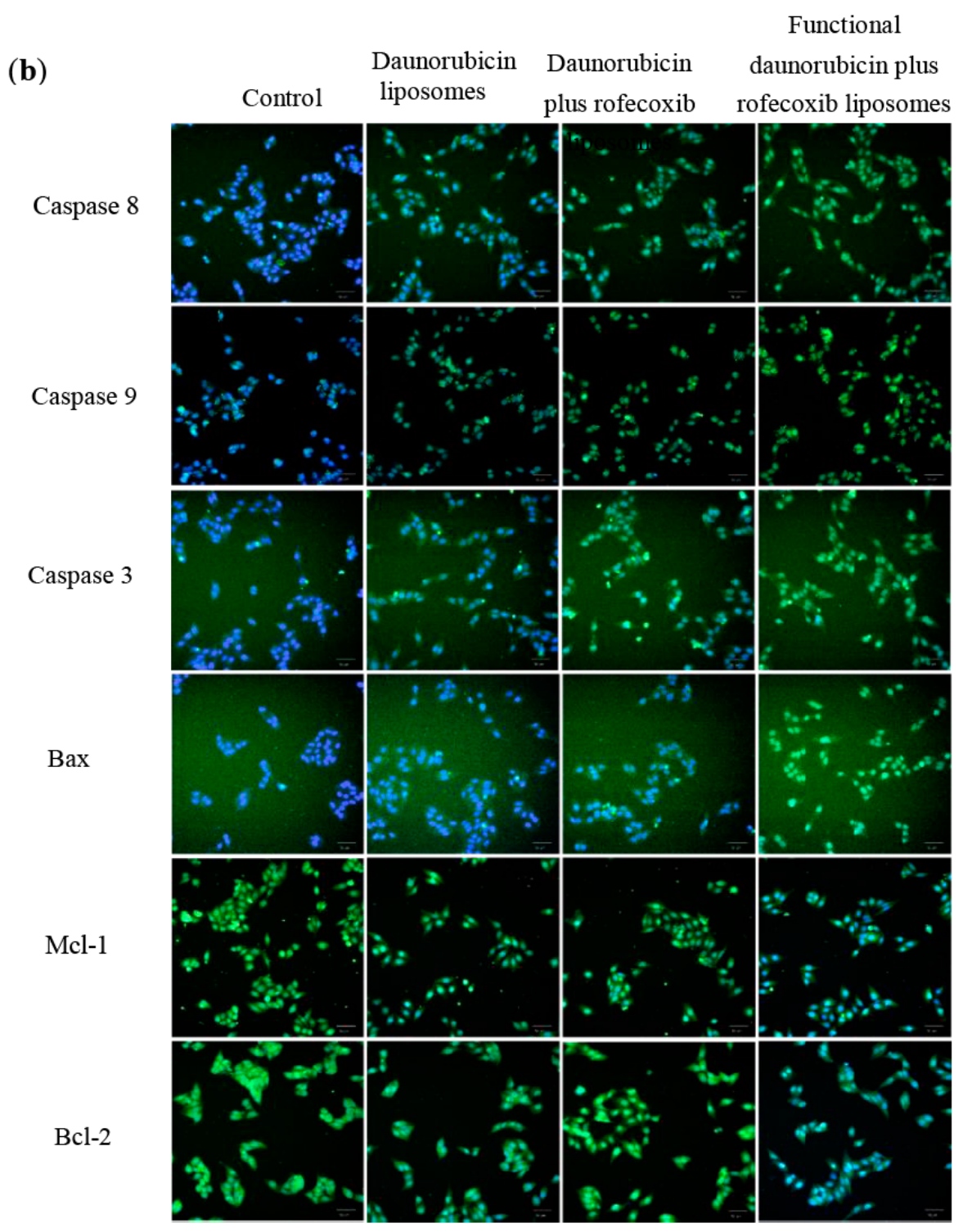

Figure 5b. Induction of apoptosis and changes of apoptosis proteins in the signaling pathway in breast cancer cells. Notes: (b) Expressions of apoptosis proteins in MCF-7 cells Operetta high-content imaging system with Columbus system; Scale bar, $50 \mathrm{~nm}$. (c) Activated Caspases enzymes and apoptosis proteins in MCF-7 cells by an Operetta high-content imaging system with the Columbus system; (d) Changes of apoptosis proteins in MCF-7 cells by Operetta high-content imaging system with Columbus system; (e) Fluorescence intensity of ROS levels of human breast cancer MCF-7 cells; (f) ROS activity ratio of human breast cancer MCF-7 cells. 1, blank control; 2, free daunorubicin; 3, daunorubicin liposomes; 4, daunorubicin plus rofecoxib liposomes; 5 , functional daunorubicin plus rofecoxib liposomes. $P<0.05 ; a$, vs $1 ; b, v s 2 ; c, v s 3 ; d$, vs 4 . Data are presented as mean \pm standard deviation $(n=3)$.

\section{Improving cytotoxicity to breast cancer cells}

To illustrate the killing effects on breast cancer cells after treatment with various formulations in vitro, inhibitory effects were studied with an SRB assay. After treatment with various liposome formulations, functional daunorubicin plus rofecoxib liposomes enhanced the killing effects on both types of cancer cells significantly compared with controls (Figure 6A and B). The ranking for the inhibitory effects on MCF-7 cells or MDAMB-231 cells was functional daunorubicin plus rofecoxib liposomes $>$ daunorubicin plus rofecoxib liposomes $>$ daunorubicin liposomes. The results demonstrated that the functional daunorubicin plus rofecoxib liposomes had the strongest killing effects on both types of cancer cells. Further, rofecoxib liposomes and blank functional liposomes themselves did not show significant cytotoxic effects on the two types of cancer cells. 

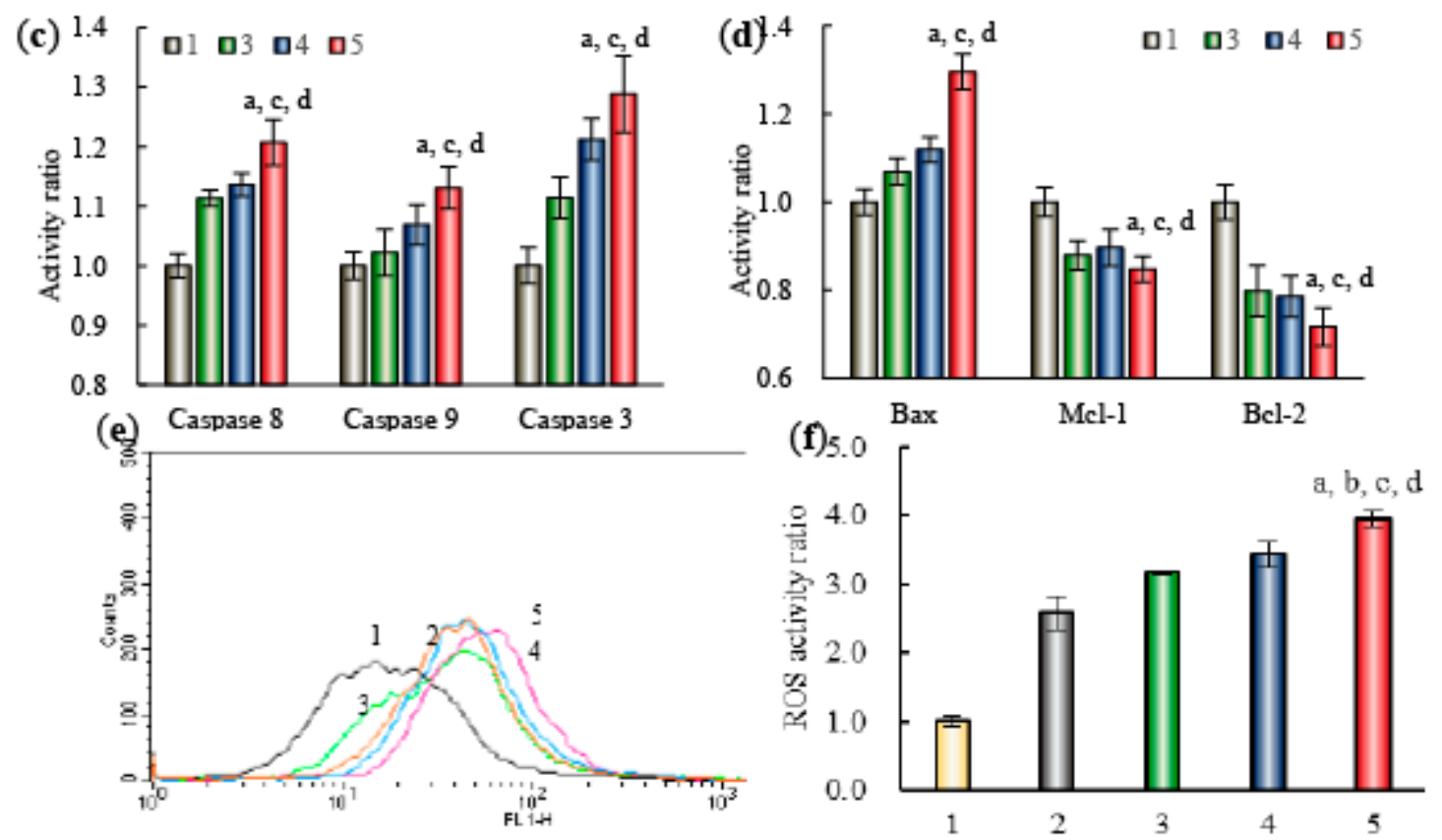

Figure 5(c) Activated Caspases enzymes and apoptosis proteins in MCF-7 cells by an Operetta high-content imaging system with the Columbus system; (d) Changes of apoptosis proteins in MCF-7 cells by Operetta high-content imaging system with Columbus system; (e) Fluorescence intensity of ROS levels of human breast cancer MCF-7 cells; (f) ROS activity ratio of human breast cancer MCF-7 cells. 1, blank control; 2, free daunorubicin; 3, daunorubicin liposomes; 4, daunorubicin plus rofecoxib liposomes; 5 , functional daunorubicin plus rofecoxib liposomes. $P<0.05 ; a, v s 1 ; b, v s 2 ; c, v s 3 ; d$, vs 4 . Data are presented as mean \pm standard deviation $(n=3)$.

\section{Enhancing anticancer efficacy in nude mice} in vivo

To evaluate drug distribution and anticancer efficacy in vivo, a human breast cancer MCF-7 cell-bearing nude mice model was constructed successfully. To observe drug distribution in real-time, 1, 1'-dioctadecyl3,3,3',3'-tetramethylindocarbocyanine iodide (DiR)-labeled functional liposomes were administered (i.v.) to cancer cell-bearing mice and observed by an imaging system in vivo. After administration of functional DiR liposomes, a strong DiR fluorescent signal was observed in the blood circulation and in cancer tissue, in which the fluorescence signal was maintained for $\leq 36$ hours. In contrast, after administration of DiR liposomes, the fluorescence signal in cancer tissue decreased gradually at 12 hours whereas, after administration of free DiR, the fluorescence signal was mainly in the liver (Supplementary Figure S6A). Thirty-six hours after administration, animals were terminated, and cancer tissues and major organs isolated for optical imaging ex vivo. The results showed that the fluorescence signal was obvious in cancer tissue after administration of functional DiR liposomes. In contrast, the fluorescence signal was not observed in cancer tissues after administration of free DiR. In addition, strong fluorescence signals could be detected in the liver and spleen after administration of all DiR formulations (Supplementary Figure S6B).

The results demonstrated that all treatment groups showed significant anticancer efficacy compared with the control (physiologic saline), and that the functional daunorubicin plus rofecoxib liposomes had the strongest anticancer efficacy in terms of cancer volume ratio (Figure 6C). The tumor inhibition at 20 days after incubation was $35.05 \pm 11.44 \%$ for daunorubicin, $41.97 \pm 12.40 \%$ for daunorubicin liposomes, $50.95 \pm 7.25 \%$ for daunorubicin plus rofecoxib liposomes, and $67.04 \pm 4.51 \%$ for functional daunorubicin plus rofecoxib liposomes. At the end of the experiment, the weights of cancer masses ex vivo from different treatment groups confirmed that the functional daunorubicin plus rofecoxib liposomes exhibited the most significant efficacy as compared with controls.

To illustrate the safety of liposomes, body weights of mice were recorded during drug administration, and blood examinations are undertaken at the end of drug administration. The results showed that the body weights and blood indices of mice were not affected significantly during administrations (Figure 6D, Supplementary Table S2). 


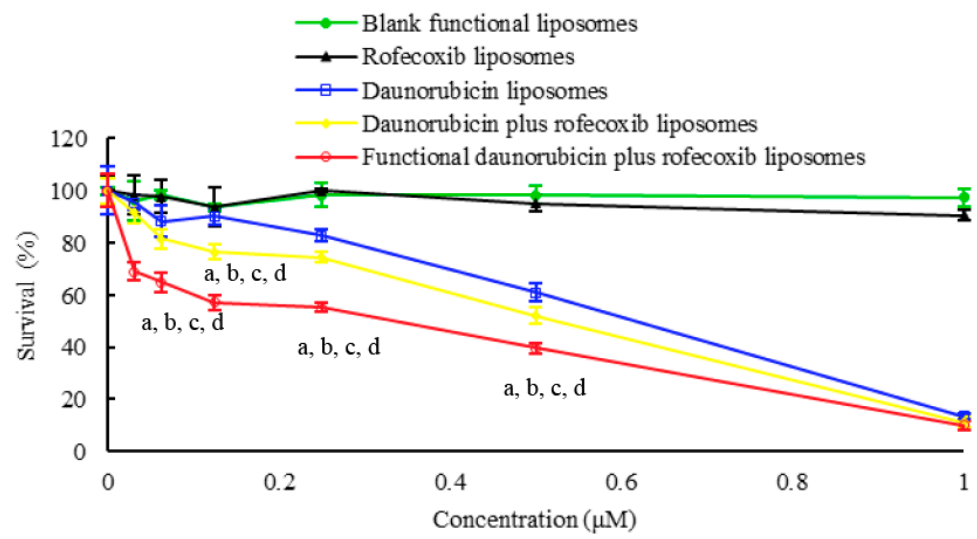

(b)

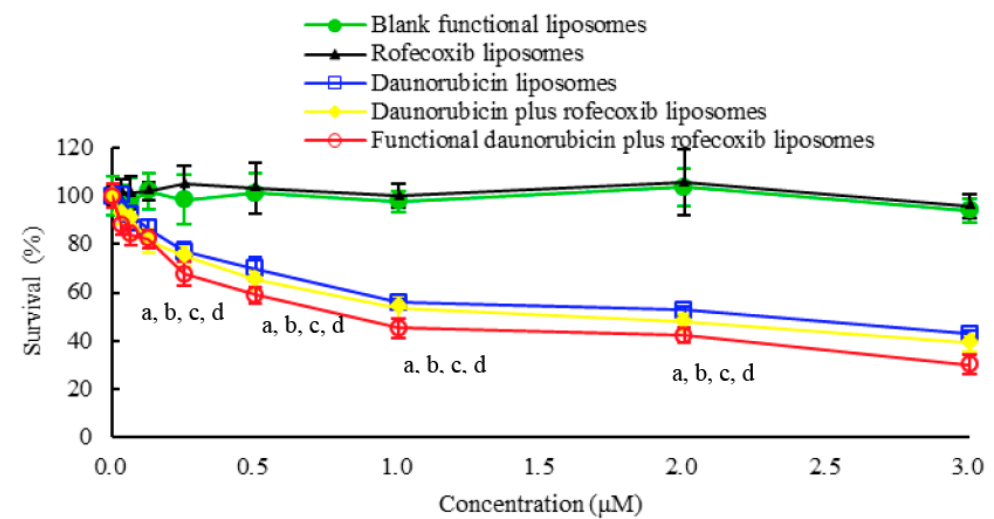

(c)

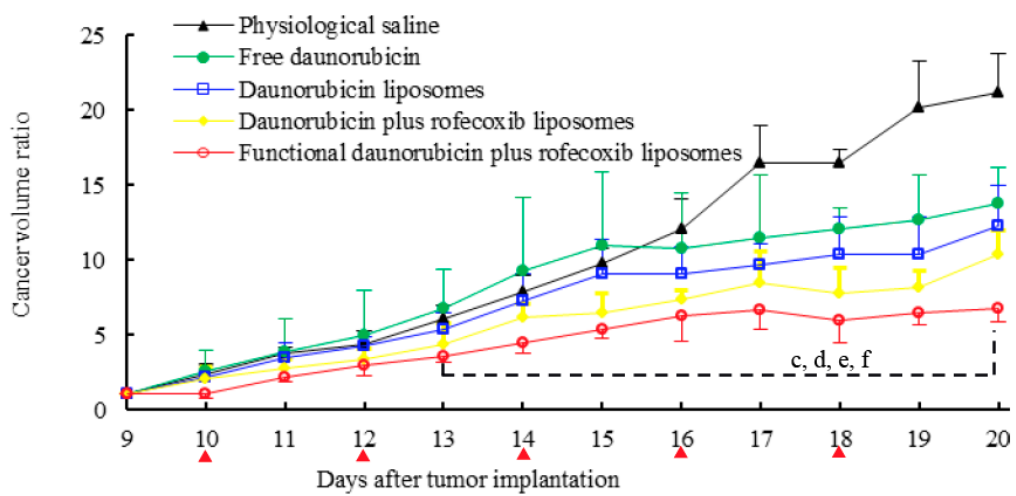

(d)

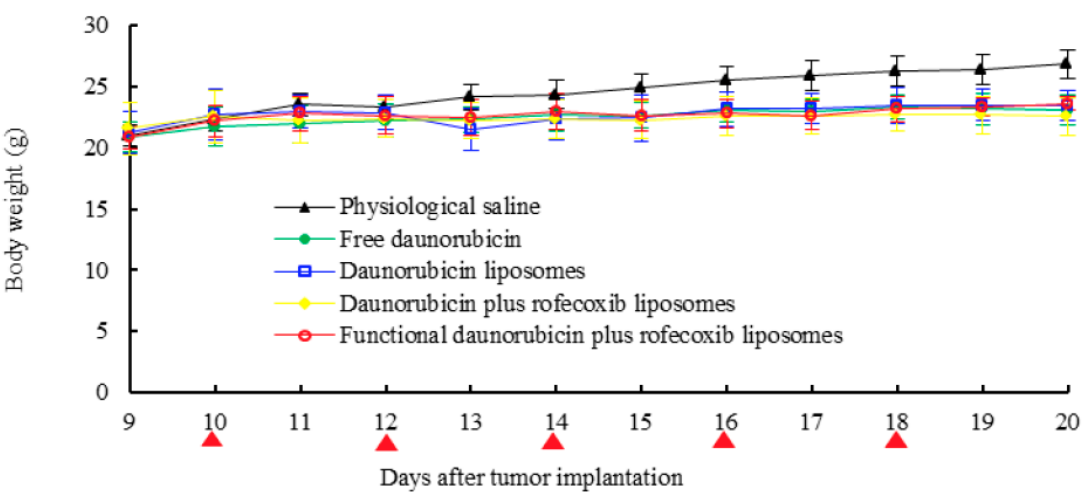

Figure 6. Killing effects in breast cancer cells and anticancer efficacy in breast cancer-bearing nude mice. Notes: (a) Cytotoxicity to MCF-7 cells. (b) Cytotoxicity to MDA-MB-231 cells. (c) Cancer volume ratios after treatments. (d) Bodyweight changes during the treatments. The arrows indicate the day of drug administration. $P<0.05$. a, vs blank functional liposomes; $b$, vs rofecoxib liposomes; $c$, vs daunorubicin liposomes; $d$, vs daunorubicin plus rofecoxib liposomes; $e$, vs saline; $f$, vs free daunorubicin. The Molar ratio of daunorubicin to rofecoxib in the liposomes was set at 1: 1. Data are presented as mean \pm standard deviation $(n=6)$. 


\section{Discussion}

A heterogeneous cancer can efflux drugs from within cells, leading to the reduced uptake of drugs by cells and resulting in the relapse and metastasis of cancer.[12, 13] To promote cellular uptake and subsequent lysosomal escape, and to initiate the programed death of cells, we constructed a kind of unique electric charge conversion liposomes, referring to as the functional drug liposomes, by encapsulating daunorubicin and rofecoxib, and modified with a new conjugate of TPGS 1000 -glutarate (Figure $1 \mathrm{~A})$.

The functional drug liposomes possess suitable physicochemical properties, including a smooth surface, a round shape (Figure 1B), nano-scale particle size, and high encapsulation efficiency (Table S1). These features allow functional drug liposomes to remain stable in the blood circulation system, and to increase the accumulation of liposome carriers into cancer tissues via the EPR effect.[14]

The functional drug liposomes can promote the cellular uptake, as evidenced by CLFM (Figure 2A and B) and by flow cytometry (Figure 2C and D, Supplementary Figure S2A and $\mathrm{B}$ ). The mechanisms are associated with the following aspects. TPGS ${ }_{1000}$-glutarate modified drug liposomes are negatively charged in the blood circulation and in the normal tissues $(\mathrm{pH}$ 7.4), while the surface electric charge of the liposomes quickly converts into positively status once arriving at the weak acidic environment of cancer tissues ( $\mathrm{pH}$ 6.5), and then positively charged liposomes are attracted by negatively charged cancer cells, thus increasing cellular uptake through adsorptivemediated endocytosis (AME).[15-7]

After endocytosis, the functional drug liposomes are entrapped by endosomes, are concentrated into lysosomes, and escape from the lysosomes (Figure 1C and Figure 3). This can be explained by the mechanism that the functional drug liposomes are further enriched into lysosomes, where the $\mathrm{pH}$ value is even lower ( $\mathrm{pH} 4.0-6.0$ ) than cancer extracellular environment.[18] The enrichment of the liposomes by lysosomes brings about a $\mathrm{pH}$ rise in lysosomes and thus simultaneously results in an internal flow of protons $\left(\mathrm{H}^{+}\right)$. Consequently, to keep the electric charge and concentration balance, a mass of chloride ions and water in the cytoplasm flow into the lysosomes as well.[19, 20] These processes finally lead to the swelling and rupture of lysosomes.[21] Accordingly, the functional drug liposomes are released into the cytosol (escape), hence avoiding the degradation by lysosomal enzymes and acidic environment.

After escape, the functional drug liposomes could exist in two states: whole vesicles and ruptured vesicles (Figure 1C). The cationic whole vesicles could be attracted onto mitochondria in response to a negative mitochondrial membrane potential.[22] whereas ruptured vesicles result in the release of daunorubicin and rofecoxib. Both the whole and the ruptured functional drug liposomes cause a cascade of biochemical reactions in heterogeneous cancer cells by inducing autophagy and apoptosis, in addition to necrosis caused by daunorubicin, as described below.

Autophagy allows orderly degradation and recycling of cellular components. Cytoplasmic constituents are isolated from the rest of the cell within a double-membraned vesicle known as an autophagosome. The latter then fuses with a lysosome and the contents are degraded and recycled. In the context of disease, autophagy can be seen as an adaptive response to stress that promotes cell survival whereas, in other cases (e.g. cytotoxic-agent stimuli), it appears to promote cell death.[23] Autophagy was evidenced by autophagosome formation induced by treatment with functional daunorubicin plus rofecoxib liposomes through the regulation of related proteins (Figure 4A and $\mathrm{B}$ ).

The central protein of autophagy, LC3B, is conjugated with phosphotidylethanolamine and incorporated into the membrane of the phagophore (autophagosome precursor), thereby initiating autophagy.[24]

The increased expression of PTEN and the reduced expressions of PI3K, Akt and mTOR suggest that the PI3K/Akt signaling pathway is suppressed by treatment with functional daunorubicin plus rofecoxib liposomes (Figure 4D). This is because the class-I PI3K/Akt (a serine/threonine-specific protein kinase, also known as $\mathrm{PKB}$ ) signaling pathway promotes cell growth in response to mitochondrial signals in cancer cells.[25] Class-I PI3K generates phosphatidylinositol $\quad(3,4) \quad \mathrm{P} 2$ and phosphatidylinositol $(3,4,5) \mathrm{P}$, which bind to the pleckstrin homology domain of Akt and its activator 3-phosphoinositide-dependent protein kinase-1 (PDK-1).[26] If the Akt 
signaling pathway is activated, autophagy is reduced. In contrast, suppression of the Akt signaling pathway induces a high rate of autophagy. Akt and PDK-1 also activate other kinases, including mTOR, which negatively regulates autophagy. The cancer suppressor PTEN, which has 3'-phosphoinositide phosphatase activity and antagonizes the PI3K/Akt pathway, positively regulates autophagy.[27] The increased expression of PTEN results in constitutive inactivation of the Akt signaling pathway, activation of autophagy and leads to cell death.[28]

Further, the increased expression of FoxO1 is involved in the induction of autophagy. FoxO1 is a type of transcription factor that initiates expression of the protein LC3 directly. FoxO1 can induce autophagy in the cytosol through its acetylation and direct binding to autophagyrelated protein 7 , resulting in the formation of LC3B.[29]

In addition, the reduced expression of P53 in cytoplasm inactivates expression of mTOR, and results in the induction of autophagy. This phenomenon can be explained by P53dependent autophagy, which is a complex (but poorly understood) signaling pathway in autophagy. In the nucleus, P53 can activate adenosine 5'-monophosphate-activated protein kinase to inhibit mTOR expression and induce autophagy. In contrast to nuclear P53, cytoplasmic P53 induces autophagy by mTOR inactivation.[30]

The results from apoptosis experiments demonstrate that the functional daunorubicin plus rofecoxib liposomes enable significant apoptosis of breast cancer cells (Figure 5A, Supplementary Figure S4A). The released daunorubicin and rofecoxib (acting as an enhancer) in the cytoplasm could initiate expression of upstream caspase 8 (initiator) and subsequently activate downstream caspase 3 (effector), leading to programmed death via a cascade of apoptotic reactions (Figure 5B and $\mathrm{C}$, Figure $\mathrm{S} 4 \mathrm{~B}$ and $\mathrm{C}$ ). Besides, the whole functional daunorubicin plus rofecoxib liposomes act on mitochondria through electric attraction (Figure S5A and B), followed by endocytosis, resulting in the opening of mitochondrial permeability transition (PT) pores, and causing the programmed death.

As for the induced apoptosis by targeting mitochondria, two mechanisms are involved in this process. The first mechanism is associated with the opening of PT pores.[31] which induces swelling of the mitochondrial matrix, resulting in rupture of the outer membrane,[32] thereby causing spillage of cytochrome $\mathrm{C}$. The second mechanism is through channels formed by protein aggregates induced by Bax (a proapoptotic gene encoding proteins belonging to the Bcl-2 family).[33] After insertion of activated Bax into the outer mitochondrial membrane, it aggregates and forms channels through which cytochrome $\mathrm{C}$ is released into the cytosol. Consequently, the released cytochrome $\mathrm{C}$ is bound with a precursor of caspase 9 to form apoptosomes, and then activates upstream caspase 9 (Figure 5B and, C, Figure S4B and C), followed by activation of the effector caspase 3 as well, resulting in a cascade of apoptotic reactions. [34, 35] In these processes, the pro-apoptotic protein Bax cab also be co-activated by suppression of expression of the anti-apoptotic protein Bcl2/Mcl-1[36, 37] by functional daunorubicin plus rofecoxib liposomes (Figure 5D, Figure S4D).

In addition, the functional daunorubicin plus rofecoxib liposomes result in a pronounced production of ROS (Figure 5E and, F, Figure $\mathrm{S} 4 \mathrm{E}$ and $\mathrm{F}$ ). ROS are chemically reactive molecules containing oxygen, which also induce apoptosis via complex pathways.[38] ROS also damage the mitochondrial membrane to release cytochrome $\mathrm{C}$, hence potentiating the apoptosis.[39]

In contributing to the overall killing effect, daunorubicin released from the ruptured liposomes is internalized by the nucleus, and result in the necrosis of cancer cells. Improved killing effects are evidenced by the cytotoxicity assay in vitro. Free daunorubicin has a restricted effect, showing intrinsic drugresistance in cells. After co-treatment with rofecoxib, functional daunorubicin plus rofecoxib liposomes display the strongest killing effect on both types of cancer cells (Figure 6A and B).

To verify overall anticancer efficacy, tumor volume is measured and calculated after treatments. Real-time imaging (Figure S6A and B) demonstrates the long duration of functional liposomes in the blood circulation system and EPR effect in cancer tissue. The in vivo study confirms that the functional daunorubicin plus rofecoxib liposomes have the strongest anticancer efficacy (Figure 6A) while do not influence on body weight and blood indicators (Figure 6B). 


\section{Conclusions}

In summary, the functional daunorubicin plus rofecoxib liposomes are developed by modifying a newly synthesized TPGS ${ }_{1000}$-glutarate. In the simulated conditions, negative charges of the functional drug liposomes at $\mathrm{pH} 7.4$ are conversed into positive charges at $\mathrm{pH}$ 6.5. The function verification studies demonstrate that the liposomes significantly promote the cellular uptake and lysosomal escape, followed by targeting the mitochondria, thus initiating a cascade of reactions through induction of autophagy and apoptosis in breast cancer cells. In conclusion, TPGS ${ }_{1000}$-glutarate modified functional drug liposomes enable the electric charge conversion to enhance treatment efficacy of breast cancer.

\section{Acknowledgements}

This work was supported by the National Natural Science Foundation of China [grant number 81373343 and 81673367]. Authors declare no conflicts of interest.

The authors declare no conflicts of interest. For signed statements, please contact the journal office: editor@precisionnanomedicine.com

Quote this article as Zhao Y, Bai J, Luo Q, Zhang JY, Xu JR, Duan JL, Yan Y, Mu LM, Lu WL, Electric charge conversable drug liposomes enable to enhance treatment efficacy of breast cancer, Prec. Nanomed. 2019;2(3):317-343, https://doi.org/10.33218/prnano2(3).190608.1

\section{Bibliography}

[1] S. S. Wong, K. M. Kim, J. C. Ting, K. Yu, J. Fu, S. Liu, R. Cristescu, M. Nebozhyn, L. Gong, Y. G. Yue, J. Wang, C. Ronghua, A. Loboda, J. Hardwick, X. Liu, H. Dai, J. G. Jin, X. S. Ye, S. Y. Kang, I. G. Do, J. O. Park, T. S. Sohn, C. Reinhard, J. Lee, S. Kim, A. Aggarwal, Genomic landscape and genetic heterogeneity in gastric adenocarcinoma revealed by whole-genome sequencing, Nat Commun. Nov 19 (2014) 5477.

[2] The Cancer Genome Atlas Network. Comprehensive molecular portraits of human breast tumours, Nature 490 (2012) 61-70.

[3] N. C. Turner, J. S. Reis-Filho, Genetic heterogeneity and cancer drug resistance, Lancet Oncol. 13 (2012) e178-185.

[4] L. G. Martelotto, C. K. Ng, S. Piscuoglio, B. Weigelt, J. S. Reisfilho, Breast cancer intra-tumor heterogeneity, Breast Cancer Res. 16 (2014) 210.

[5] K. Lotfi, A. L. Zackrisson, C. Peterson, Comparison of idarubicin and daunorubicin regarding intracellular uptake, induction of apoptosis, and resistance, Cancer Lett. 178 (2002) 141-149.

[6] G. Spizzo, G. Gastl, D. Wolf, E. Gunsilius, M. Steurer, D. Fong, A. Amberger, R. Margreiter, P. Obrist, Correlation of COX-2 and Ep-CAM overexpression in human invasive breast cancer and its impact on survival, Br. J. Cancer 88 (2003) 574-578.

[7] M. M. Gottesman, T. Fojo, S. E. Bates, Multidrug resistance in cancer: role of ATP-dependent transporters, Nat. Rev. Cancer 2 (2002) 48-58.

[8] L. Laine, S. Harper, T. Simon, R. Bath, J. Johanson, H. Schwartz, S. Stern, H. Quan, J. Bolognese, A randomized trial comparing the effect of rofecoxib, a cyclooxygenase 2-specific inhibitor, with that of ibuprofen on the gastroduodenal mucosa of patients with osteoarthritis, Rofecoxib Osteoarthritis Endoscopy Study Group. Gastroenterology 117 (1999) 776-783.

[9] Y. Matsumura, H. Maeda, A new concept for macromolecular therapeutics in cancer chemotherapy: mechanism of tumoritropic accumulation of proteins and the antitumor agent smancs, Cancer Res. 46 (1986) 6387-6392.

[10] P. Swietach, R. D. Vaughan-Jones, A. L. Harris, A. Hulikova, The chemistry, physiology and pathology of pH in cancer, Philos. Trans. R. Soc. Lond. B. Biol. Sci. 369 (2014) 20130099.

[11] C. M. Neophytou, C. Constantinou, P. Papageorgis, A. I. Constantinou, D-alpha-tocopheryl polyethylene glycol succinate (TPGS) induces cell cycle arrest and apoptosis selectively in Survivinoverexpressing breast cancer cells, Biochem. Pharmacol. 89 (2014) 31-42.

[12] C. K. Ng, H. N. Pemberton, J. S. Reis-Filho, Breast cancer intratumor genetic heterogeneity: causes and implications, Expert Rev. Anticancer Ther. 12, 1021-1032 (2012). 
[13] X. Ma, J. Zhou, C. X. Zhang, X. Y. Li, N. Li, R. J. Ju, J. F. Shi, M. G. Sun, W. Y. Zhao, L. M. $\mathrm{Mu}, \mathrm{Y}$. Yan, W. L. Lu, Modulation of drug-resistant membrane and apoptosis proteins of breast cancer stem cells by targeting berberine liposomes, Biomaterials 34 (2013) 4452-4465.

[14] R. Kayyali, C. Marriott, H. Wiseman, Tamoxifen decreases drug efflux from liposomes: relevance to its ability to reverse multidrug resistance in cancer cells? FEBS letters 344 (1994) 221224.

[15] L. Li, Q. Yang, Z. Zhou, J. Zhong, Y. Huang, Doxorubicin-loaded, charge reversible, folate modified HPMA copolymer conjugates for active cancer cell targeting, Biomaterials 35 (2014) 51715187.

[16] S. S. Han, Z. Y. Li, J. Y. Zhu, K. Han, Z. Y. Zeng, W. Hong, W. X. Li, H. Z. Jia, Y. Liu, R. X. Zhuo, X. Z. Zhang, Dual-pH Sensitive Charge-Reversal Polypeptide Micelles for Tumor-Triggered Targeting Uptake and Nuclear Drug Delivery, Small. 11 (2015) 2543-2554.

[17] M. M. Chen, F. F. Song, M. Feng, Y. Liu, Y. Y. Liu, J. Tian, F. Lv, Q. Q. Zhang, pH-sensitive charge-conversional and NIR responsive bubble-generating liposomal system for synergetic thermochemotherapy, Colloids and Surfaces B: Biointerfaces. 167 (2018) 104-114.

[18] G. F. Luo, W. H. Chen, Y. Liu, J. Zhang, S. X. Cheng, R. X. Zhuo, X. Z. Zhang, Charge-reversal plug gate nanovalves on peptide-functionalized mesoporous silica nanoparticles for targeted drug delivery, J. Mater. Chem. B. 1 (2013) 5723-5732.

[19] J. A. Mindell, Lysosomal acidification mechanisms, Annu Rev Physiol. 74 (2012) 69-86.

[20] A. R. Graves, P. K. Curran, C. L. Smith, J. A. Mindell, The $\mathrm{Cl}^{-} / \mathrm{H}^{+}$antiporter ClC-7 is the primary chloride permeation pathway in lysosomes, Nature 453 (2008) 788-792.

[21] A. E. Nel, L. Mädler, D. Velegol, T. Xia, E. M. V. Hoek, P. Somasundaran, F. Klaessig, V. Castranova, M. Thompson, Understanding biophysicochemical interactions at the nano-bio interface, Nature Materials. 8 (2009) 543-557.

[22] J. S. Modica-Napolitano, J. R. Aprille, Delocalized lipophilic cations selectively target the mitochondria of carcinoma cells, Adv. Drug. Deliv. Rev. 49 (2001) 63-70.

[23] Y. Liu, M. Schiff, K. Czymmek, Z. Tallóczy, B. Levine, S. P. Dinesh-Kumar, Autophagy regulates programmed cell death during the plant innate immune response, Cell 121 (2005) 567-577.

[24] J. Huang, W. Pan, D. Ou, W. Dai, Y. Lin, Y. Chen, X. Chen, LC3b, a protein that serves as an autophagic marker, modulates angiotensin ii-induced myocardial hypertrophy. J. Cardiovasc, Pharmacol. 66 (2015) 576-583.

[25] P. Blume-Jensen, T. Hunter, Oncogenic kinase signaling, Nature 411 (2001) 355-365.

[26] A. J. Meijer, P. Codogno, Regulation and role of autophagy in mammalian cells, Int. J. Biochem. Cell Biol. 36 (2004) 2445-2462.

[27] S. Arico, A. Petiot, C. Bauvy, P. F. Dubbelhuis, A. J. Meijer, P. Codogno, E. Ogier-Denis, The tumor suppressor PTEN positively regulates macroautophagy by inhibiting the phosphatidylinositol 3kinase/protein kinase B pathway, J. Biol. Chem. 276 (2001) 35243-35246.

[28] T. Shintani, D. J. Klionsky, Autophagy in health and disease: a double-edged sword, Science 306 (2004) 990-995.

[29] L. Galluzzi, F. Pietrocola, B. Levine, G. Kroemer, Metabolic control of autophagy, Cell 159 (2014) 1263-1276.

[30] L. Ringer, P. Sirajuddin, L. Tricoli, S. Waye, M. U. Choudhry, E. Parasido, A. Sivakumar, M. Heckler, A. Naeem, I. Abdelgawad, X. Liu, A. S. Feldman, R. J. Lee, C. L. Wu, V. Yenugonda, B. Kallakury, A. Dritschilo, J. Lynch, R. Schlegel, O. Rodriguez, R. G. Pestell, M. L. Avantaggiati, C. Albanese, The induction of the p53 tumor suppressor protein bridges the apoptotic and autophagic signaling pathways to regulate cell death in prostate cancer cells, Oncotarget 5 (2014) 10678-10691.

[31] R. Kumarswamy, R. K. Seth, B. S. Dwarakanath, S. Chandna, Mitochondrial regulation of insect cell apoptosis: evidence for permeability transition pore-independent cytochrome-c release in the Lepidopteran Sf9 cells, Int. J. Biochem. Cell Biol. 41 (2009) 1430-1440.

[32] L. Galluzzi, K. Blomgren, G. Kroemer, Mitochondrial membrane permeabilization in neuronal injury, Nat. Rev. Neurosci. 10 (2009) 481-494.

[33] J. M. Jürgensmeier, Z. Xie, Q. Deveraux, L. Ellerby, D. Bredesen, J. C. Reed, Bax directly induces release of cytochrome c from isolated mitochondria, Proc. Natl. Acad. Sci. USA 95 (1998) 4997-5002. 
[34] S. Shimizu, M. Narita, Y. Tsujimoto, Bcl-2 family proteins regulate the release of apoptogenic cytochrome c by the mitochondrial channel VDAC, Nature 399 (1999) 483-487.

[35] J. Grohm, N. Plesnila, C. Culmsee, Bid mediates fission, membrane permeabilization and perinuclear accumulation of mitochondria as a prerequisite for oxidative neuronal cell death. Brain Behav, Immun. 24 (2010) 831-838.

[36] P. J. Dlugosz, L. P. Billen, M. G. Annis, W. Zhu, Z. Zhang, J. Lin, B. Leber, D. W. Andrews, Bcl-2 changes conformation to inhibit Bax oligomerization, Embo. J. 25 (2006) 2287-2296.

[37] G. Marino, C. Lopez-Otin, Autophagy: molecular mechanisms, physiological functions and

[38] Y. L. Lo, W. Wang, Formononetin potentiates epirubicin-induced apoptosis via ROS production in HeLa cells in vitro, Chem. Biol. Interact. 205 (2013) 188-197.

[39] A. Villunger, A. Egle, M. Kos, B. L. Hartmann, S. Geley, R. Kofler, R. Greil, Drug-induced apoptosis is associated with enhanced Fas (Apo-1/CD95) ligand expression but occurs independently of Fas (Apo-1/CD95) signaling in human T-acute lymphatic leukemia cells, Cancer Res. 57 (1997) 3331-3334. 


\section{Supporting Information}

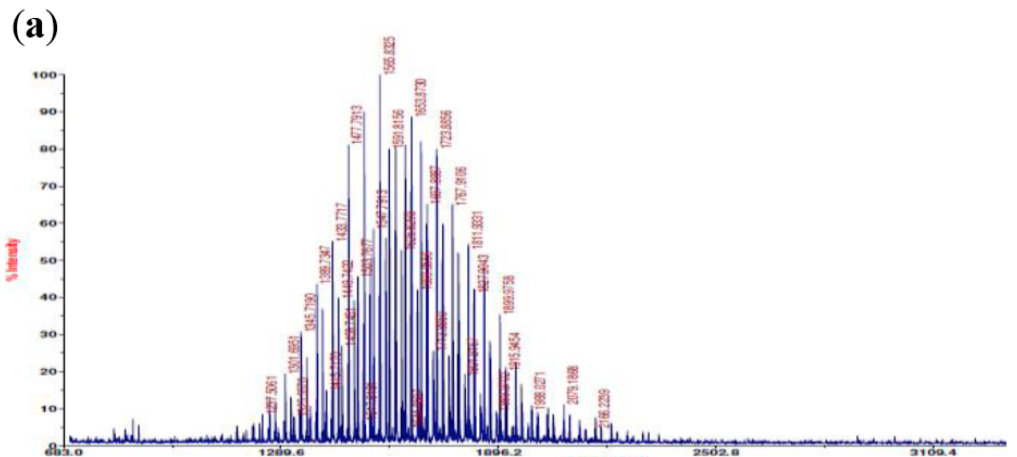

(b)

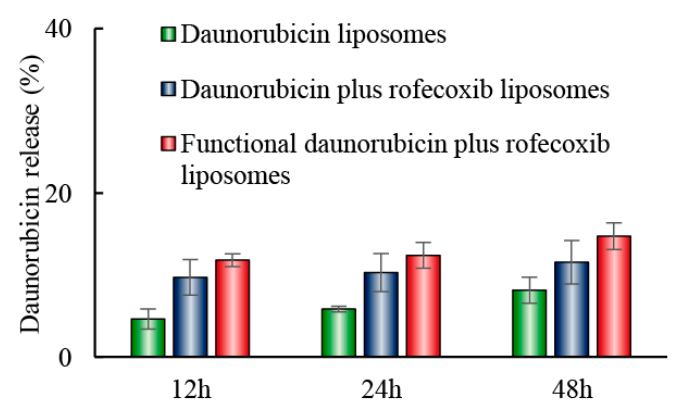

(c)

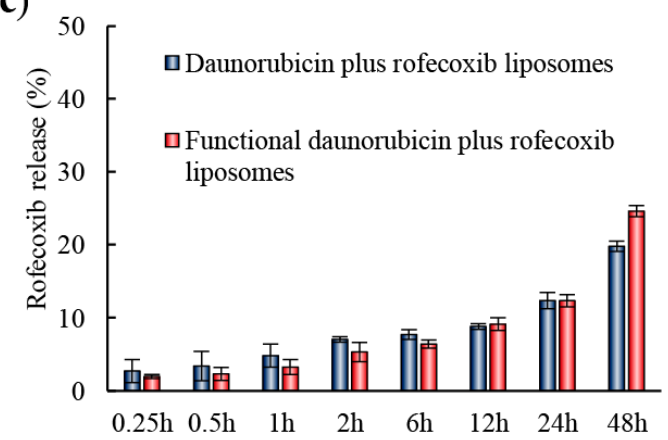

Fig. S1 Characterization of functional daunorubicin plus rofecoxib liposomes

Notes: (a) MALDI-TOF-MS spectra of TPGS1000-glutarate conjugate. (b) In vitro release rates of daunorubicin from the liposomes in the simulated blood fluids. (c) In vitro release rates of rofecoxib from the liposomes in the simulated blood fluids. Data are presented as mean \pm standard deviation $(n=3)$. 

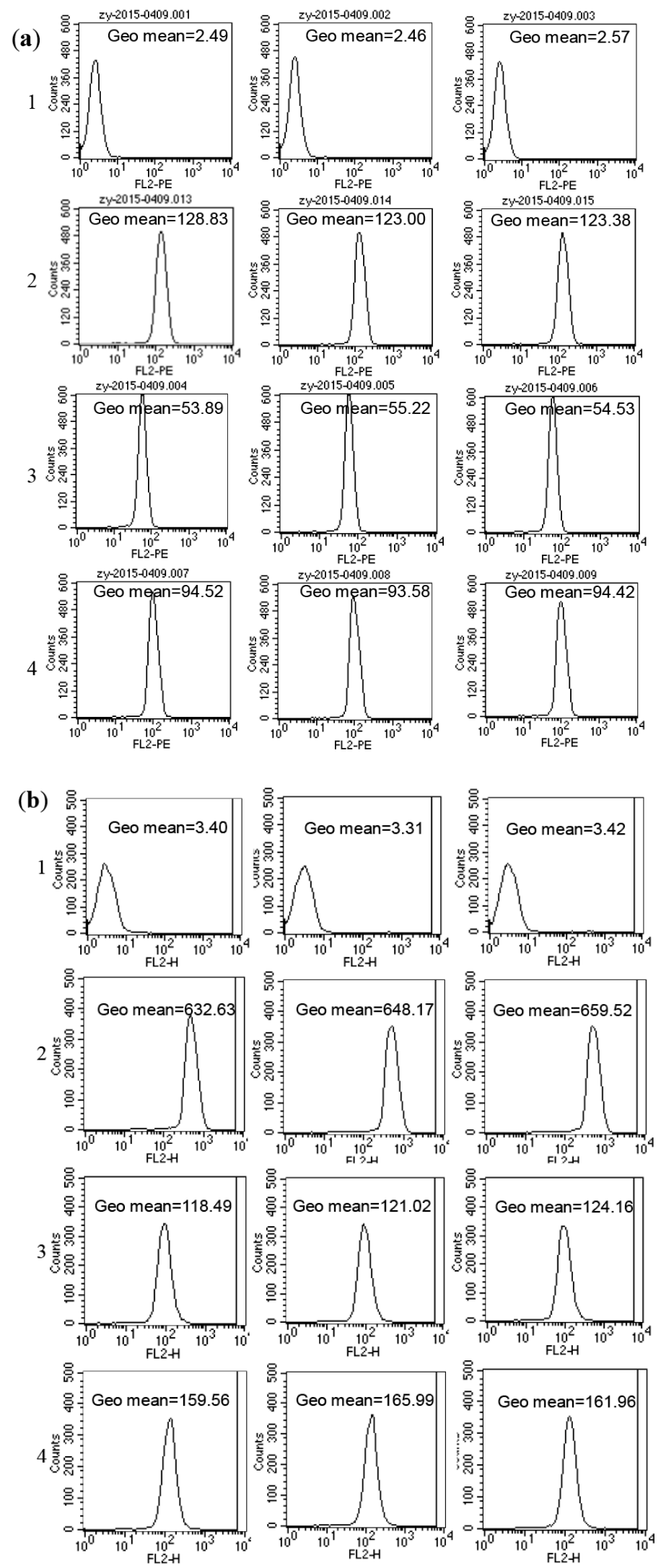

Fig. S2 Cellular uptake by breast cancer cells after treatment. Notes: (a) Cellular uptake by MCF-7 cells indicated by fluorescence intensity. (b) Cellular uptake by MDA-MB-231 indicated by fluorescence intensity. 1, blank control; 2, free daunorubicin; 3, daunorubicin liposomes; 4, functional daunorubicin liposomes. 


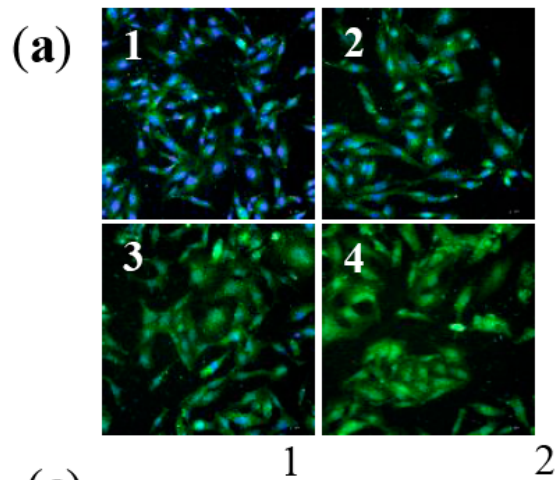

(b)
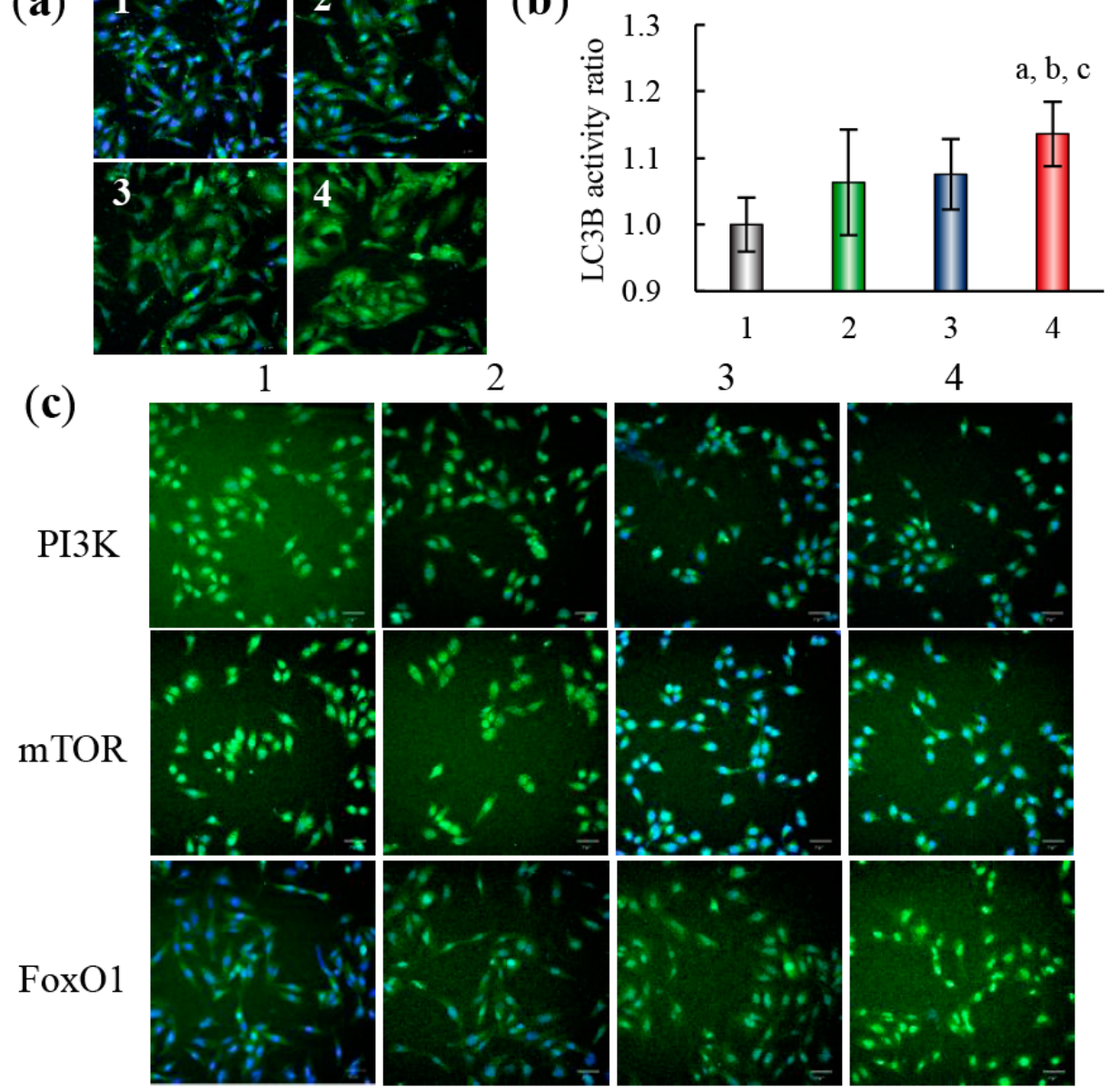

(d)

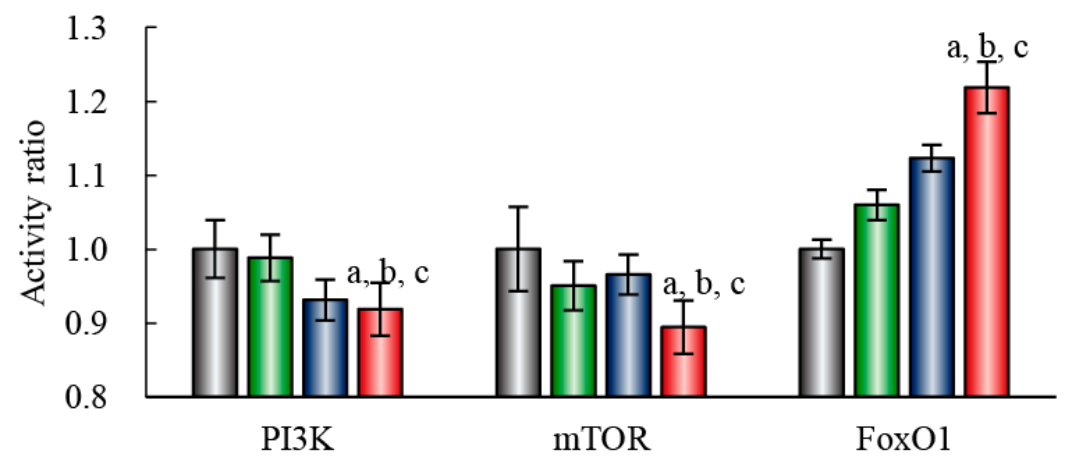

Fig. S3 Induction of autophagy and changes of autophagy proteins in the signaling pathway in breast cancer cells after treatment. Notes: The assays were performed by Operetta high-content imaging system with Columbus system. (a) Fluorescence intensities of $L C 3 B$ in $M D A-M B-231$ cells. (b) Activity ratios of LC3B in MDA-MB-231 cells. (c) Autophagy proteins in the signaling pathways in MDA-MB-231 cells. (d) Autophagy proteins in the signaling pathways in MDA-MB-231 cells. 1, blank control; 2, daunorubicin liposomes; 3, daunorubicin plus rofecoxib liposomes; 4, functional daunorubicin plus rofecoxib liposomes. $P<0.05$; $a$, vs $1 ; b, v s 2$; $c$, vs 3 . Data are presented as mean \pm standard deviation ( $n=3)$. 
(a)
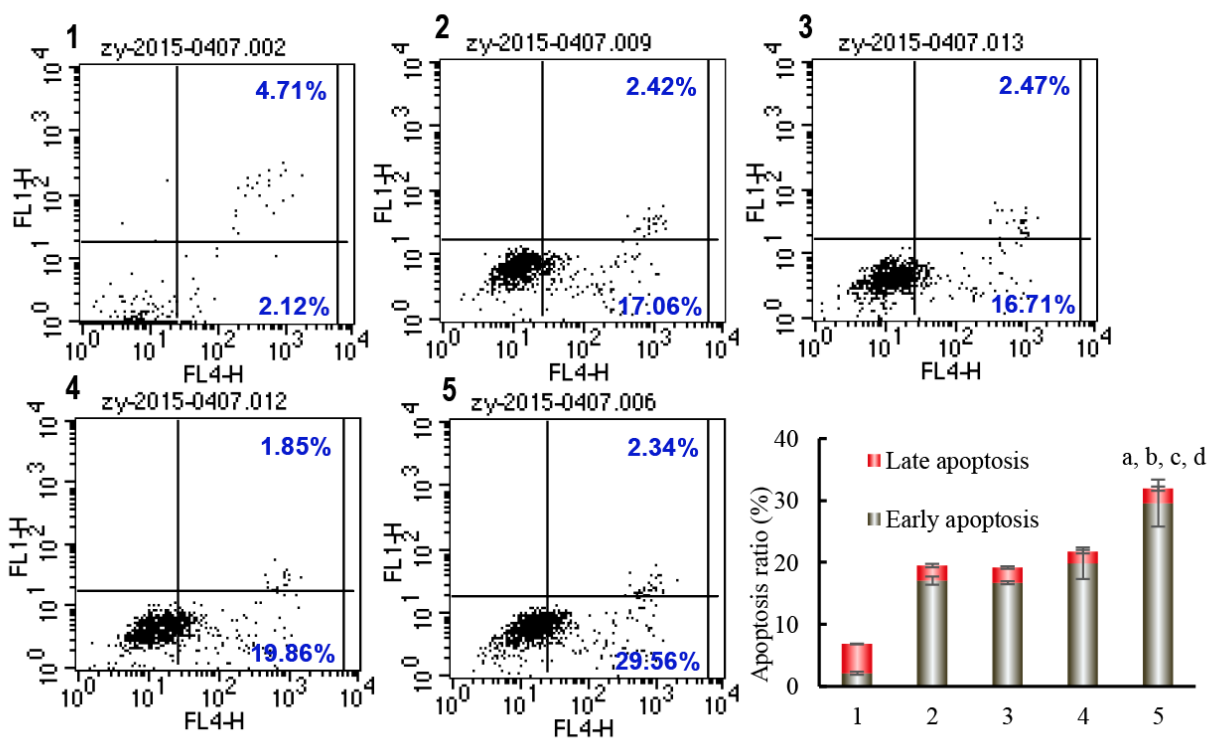

(b)

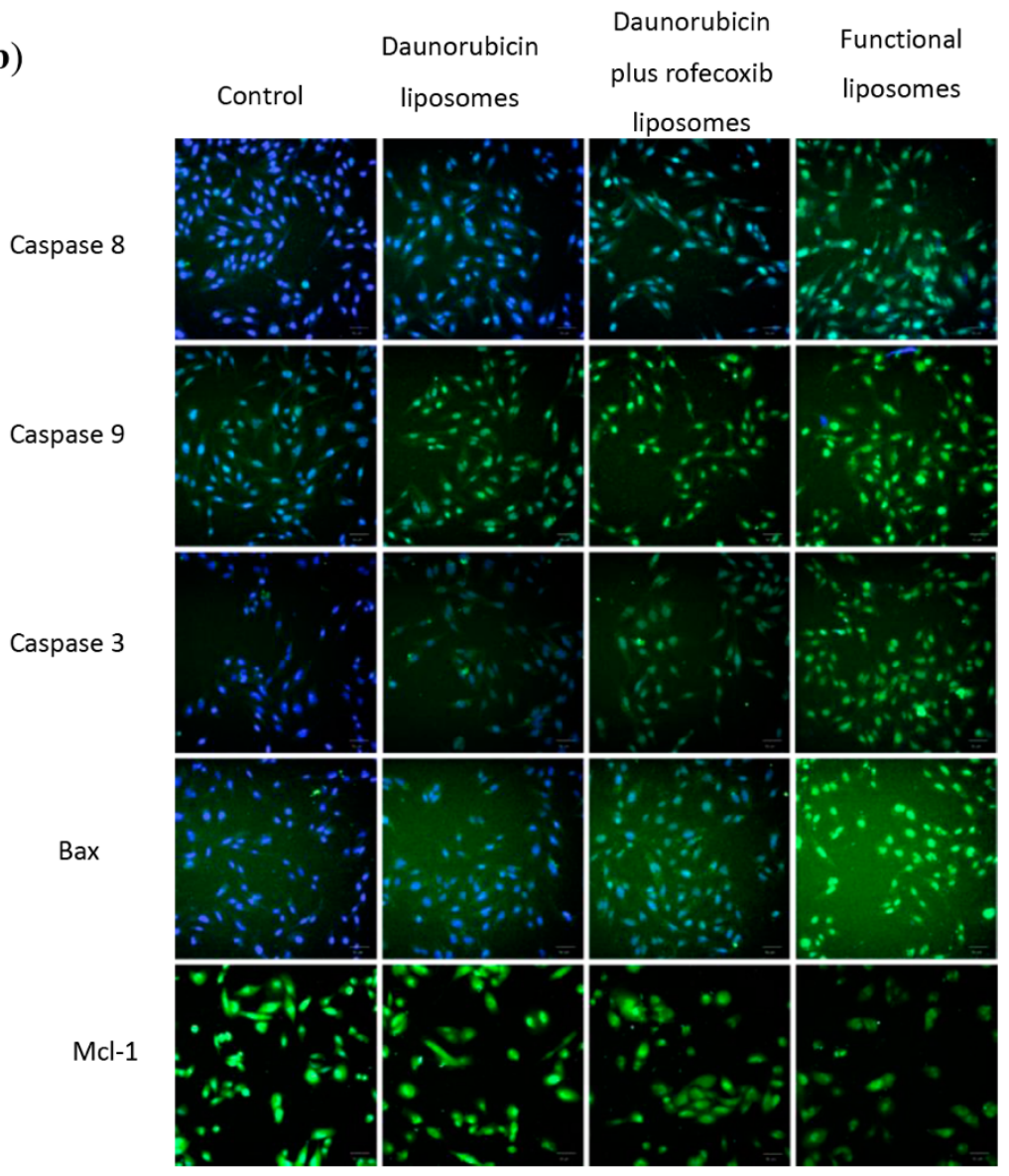

Fig. S4. Changes of apoptosis proteins in the signaling pathway in breast cancer cells after treatment. Notes: (a) Apoptosis of MDA-MB-231 cells by flow cytometry; (b) Expressions of apoptosis proteins in MDA-MB-231 cells by Operetta high-content imaging system with Columbus system; Scale bar, $50 \mathrm{~nm}$. (c) Activated Caspases enzymes in MDA-MB-231 cells by Operetta high-content imaging system with Columbus system. (d) Changes of apoptosis proteins in MDA-MB-231 cells by Operetta high-content imaging system with Columbus system. (e) Fluorescence intensity of ROS levels of triple-negative breast cancer $M D A-M B-231$ cells. (f) ROS activity ratio in MDA-MB-231 cells. 1, blank control; 2, free daunorubicin; 3, daunorubicin liposomes; 4, daunorubicin plus rofecoxib liposomes; 5 , functional daunorubicin plus rofecoxib liposomes. $P<0.05$; a, vs 1 ; $b$, vs $2 ; c, v s 3 ; d, v s 4$. Data are presented as mean \pm standard deviation $(n=3)$. 


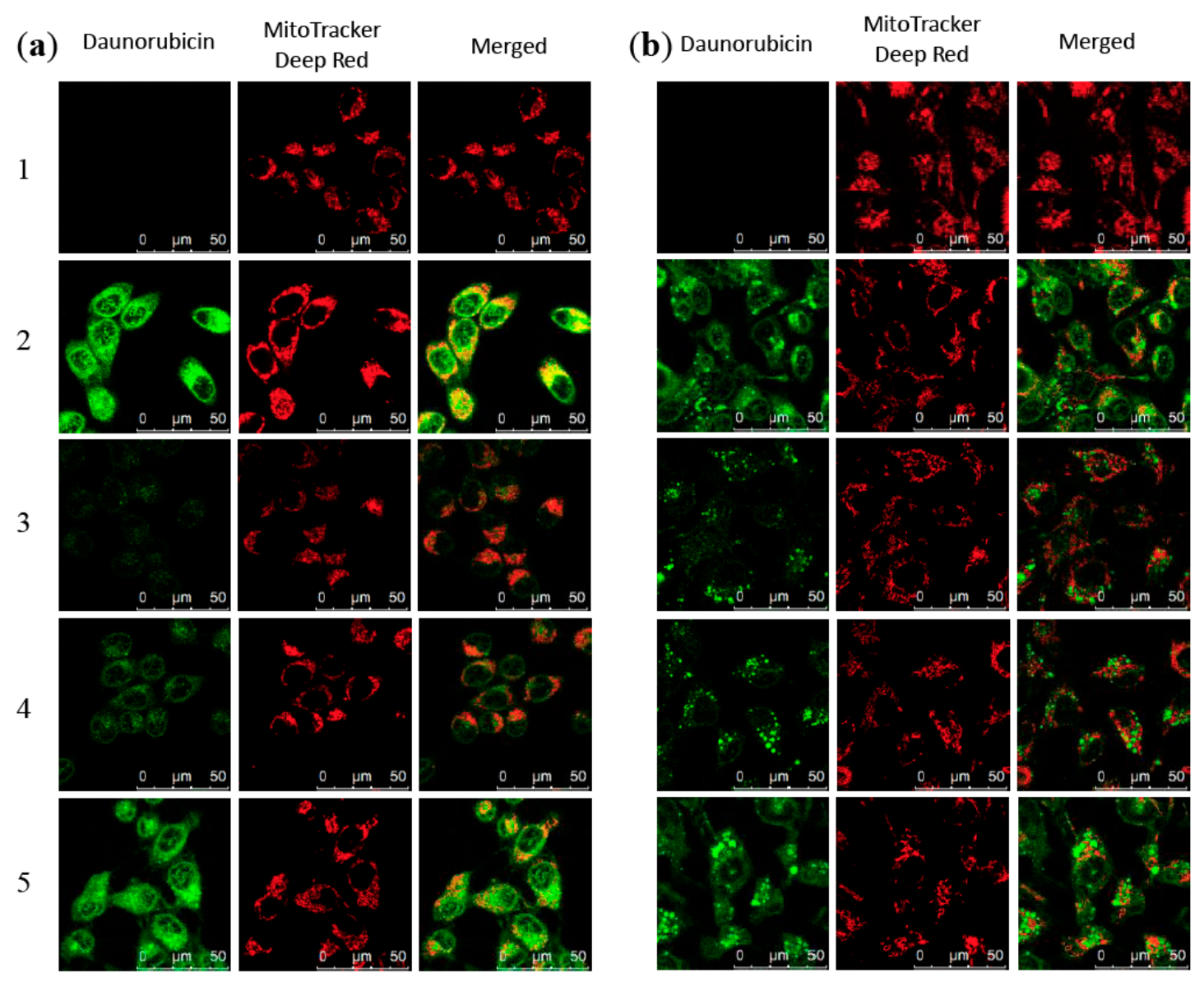

Fig. S5 Mitochondria co-localization of functional daunorubicin plus rofecoxib liposomes in breast cancer cells after treatment. Notes: The assays were performed by confocal laser fluorescent microscopy. (a) MCF-7 cells. (b) MDA-MB-231 cells. 1, blank control; 2, free daunorubicin; 3, daunorubicin liposomes; 4, daunorubicin plus rofecoxib liposomes; 5, functional daunorubicin plus rofecoxib liposomes.

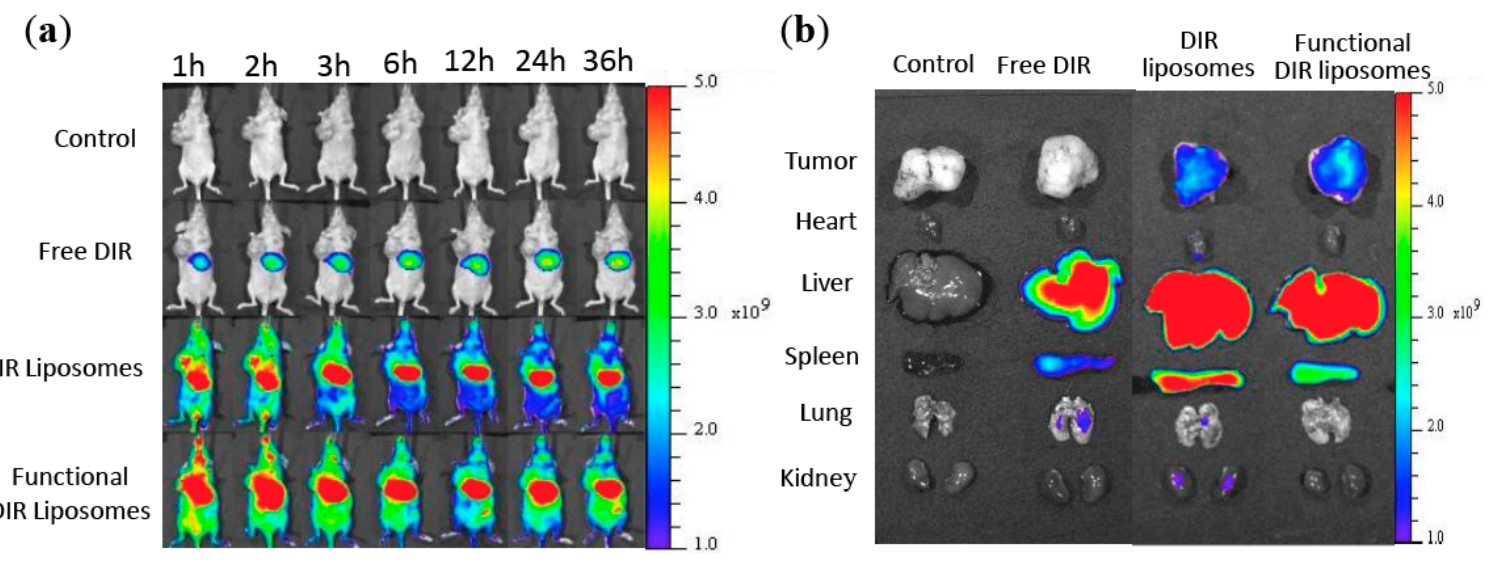

Fig. S6 In vivo imaging drug distribution in breast cancer-bearing nude mice after intravenous administration. Notes: (a) In vivo real-time images of functional DiR liposomes; (b) Ex vivo images of cancer masses and major organs at $36 \mathrm{~h}$. 
Table S1. Characterization of liposomes.

\begin{tabular}{|c|c|c|c|c|c|}
\hline \multirow[t]{2}{*}{ Liposomes } & \multirow[t]{2}{*}{$\begin{array}{l}\text { Mean size } \\
\quad(\mathrm{nm})\end{array}$} & \multirow[t]{2}{*}{ PDI } & \multirow[t]{2}{*}{$\begin{array}{l}\text { Zeta potential } \\
(\mathrm{mV})\end{array}$} & \multicolumn{2}{|c|}{$\begin{array}{c}\text { Encapsulation efficiency } \\
(\%)\end{array}$} \\
\hline & & & & Daunorubicin & Rofecoxib \\
\hline $\begin{array}{l}\text { Blank } \\
\text { functional } \\
\text { liposomes }\end{array}$ & $81.48 \pm 0.78$ & $0.190 \pm 0.011$ & $-11.43 \pm 0.75$ & & \\
\hline $\begin{array}{l}\text { Daunorubicin } \\
\text { liposomes }\end{array}$ & $75.25 \pm 2.41$ & $0.221 \pm 0.032$ & $-2.70 \pm 0.05$ & $91.7 \pm 2.3$ & \\
\hline $\begin{array}{l}\text { Rofecoxib } \\
\text { liposomes }\end{array}$ & $82.25 \pm 0.48$ & $0.210 \pm 0.009$ & $-3.44 \pm 0.22$ & & $90.3 \pm 0.7$ \\
\hline $\begin{array}{l}\text { Daunorubicin } \\
\text { plus rofecoxib } \\
\text { liposomes }\end{array}$ & $87.00 \pm 0.15$ & $0.212 \pm 0.006$ & $\begin{array}{l}-6.42 \pm 0.65(\mathrm{pH} 7.4) \\
-4.09 \pm 0.72(\mathrm{pH} \\
6.5)\end{array}$ & $93.9 \pm 2.7$ & $87.1 \pm 1.5$ \\
\hline $\begin{array}{l}\text { Functional } \\
\text { daunorubicin } \\
\text { plus rofecoxib } \\
\text { liposomes }\end{array}$ & $84.51 \pm 0.90$ & $0.219 \pm 0.016$ & $\begin{array}{l}-10.02 \pm 0.73(\mathrm{pH} \\
7.4) \\
2.81 \pm 1.42(\mathrm{pH} 6.5)\end{array}$ & $97.0 \pm 1.4$ & $83.1 \pm 3.6$ \\
\hline
\end{tabular}

Table S2. Blood examinations of breast cancer-bearing nude mice after administration.

\begin{tabular}{llllll}
\hline Assay & Saline & $\begin{array}{l}\text { Free } \\
\text { daunorubicin }\end{array}$ & $\begin{array}{l}\text { Daunorubicin } \\
\text { liposomes }\end{array}$ & $\begin{array}{l}\text { Daunorubicin } \\
\text { plus Rofecoxib } \\
\text { liposomes }\end{array}$ & $\begin{array}{l}\text { Functional } \\
\text { daunorubicin } \\
\text { +rofecoxib } \\
\text { liposomes }\end{array}$ \\
\hline $\mathrm{WBC}^{\mathrm{a}}\left(10^{9} / \mathrm{L}\right)$ & $4.95 \pm 0.42$ & $5.00 \pm 0.82$ & $5.10 \pm 0.76$ & $4.03 \pm 0.46^{*}$ & $4.77 \pm 0.87$ \\
$\mathrm{RBC}^{\mathrm{b}}\left(10^{12} / \mathrm{L}\right)$ & $7.15 \pm 0.44$ & $5.50 \pm 0.75^{*}$ & $5.88 \pm 0.42^{*}$ & $5.81 \pm 0.76^{*}$ & $5.66 \pm 0.75^{*}$ \\
$\mathrm{HGB}^{\mathrm{c}}(\mathrm{g} / \mathrm{L})$ & $12.67 \pm 1.12$ & $9.67 \pm 1.50^{*}$ & $10.33 \pm 1.00^{*}$ & $10.10 \pm 1.37^{*}$ & $9.90 \pm 0.74^{*}$ \\
$\mathrm{MCV}^{\mathrm{d}}(\mathrm{fL})$ & $53.57 \pm 1.14$ & $53.58 \pm 1.60$ & $52.80 \pm 0.81$ & $52.06 \pm 1.42$ & $52.77 \pm 1.37$ \\
$\mathrm{MCH}^{\mathrm{e}}(\mathrm{pg})$ & $17.70 \pm 0.83$ & $17.98 \pm 0.74$ & $17.52 \pm 0.50$ & $17.07 \pm 0.60$ & $17.41 \pm 1.04$ \\
$\mathrm{RDW}^{\mathrm{f}}(\%)$ & $14.31 \pm 0.82$ & $14.2 \pm 1.04$ & $12.93 \pm 0.61$ & $13.35 \pm 0.76$ & $13.52 \pm 1.09$ \\
$\mathrm{PDW}^{\mathrm{h}}(\%)$ & $13.77 \pm 0.69$ & $14.61 \pm 0.73$ & $14.46 \pm 0.73$ & $14.62 \pm 0.50$ & $14.23 \pm 0.93$ \\
$\mathrm{GRN}^{\mathrm{i}}\left(10^{9} / \mathrm{L}\right)$ & $4.53 \pm 0.51$ & $4.23 \pm 0.47$ & $4.47 \pm 0.67$ & $3.47 \pm 0.50^{*}$ & $4.60 \pm 0.40$ \\
\hline
\end{tabular}

Notes: Data are presented as the mean \pm SD $(n=3)$. a, white blood cells; b, red blood cells; c, hemoglobin; $\mathrm{d}$, mean corpuscular volume; e, mean corpuscular hemoglobin; f, red cell distribution width; $h$, platelet distribution width; i, neutrophil granulocyte. 1 . Saline. ${ }^{*} \mathrm{P}<0.05$, versus. 1 . 